\title{
Structural, Vibrational, and Electronic Properties of the Glucoalkaloid Strictosidine: A Combined Experimental and Theoretical Study
}

\author{
Renyer Alves Costa, ${ }^{1}$ Maria Lucia Belem Pinheiro, ${ }^{1}$ Kelson Mota Teixeira de Oliveira, ${ }^{1}$ \\ Andersson Barison, ${ }^{2}$ Kahlil Schwanka Salomé, ${ }^{2}$ Júlio Rodolfo Iank, \\ Noam Gadelha da Silva, ${ }^{1}$ Tiara Souza Cabral, ${ }^{3}$ and Emmanoel Vilaça Costa ${ }^{1}$ \\ ${ }^{1}$ Department of Chemistry, Federal University of Amazonas, 69077-000 Manaus, AM, Brazil \\ ${ }^{2}$ NMR Laboratory, Department of Chemistry, Federal University of Paraná, 80060-000 Curitiba, PR, Brazil \\ ${ }^{3}$ National Research Institute of Amazonas (INPA), 69080-971 Manaus, AM, Brazil
}

Correspondence should be addressed to Renyer Alves Costa; renyer.costa@gmail.com

Received 21 October 2015; Accepted 3 January 2016

Academic Editor: Arturo Espinosa Ferao

Copyright (C) 2016 Renyer Alves Costa et al. This is an open access article distributed under the Creative Commons Attribution License, which permits unrestricted use, distribution, and reproduction in any medium, provided the original work is properly cited.

\begin{abstract}
A detailed structural analysis and spectral behavior of the glucoalkaloid strictosidine, a precursor of all monoterpene indole alkaloids, are discussed. The experimental NMR, FTIR, and UV results were compared to the theoretical DFT spectra calculated by Becke using the three-parameter Lee-Yang-Parr (B3LYP) function with 6-31G(d) and 6-311++G(2d,p) basis sets. The theoretical geometry optimization data were compared with the X-ray data for precursors and similar structures in the associated literature. The similarity between the theoretical and experimental coupling constants values made it possible to affirm the values of dihedral angles and their configuration, reinforcing findings from previous stereochemical studies. Theoretical UV analysis agreed well with the measured experimental data, with bands assigned. Calculated HOMO/LUMO gaps show low excitation energy for strictosidine, justifying its stability and reaction kinetics. The molecular electrostatic potential map shows opposite potentials regions that form hydrogen bonds that stabilize the dimeric form, which were confirmed by excellent agreement of the dimeric form theoretical wavenumbers with the experimental IR spectrum. ESI-MS/MS data revealed patterns for the fragmentation of the protonated strictosidine molecule outlined by an NBO study.
\end{abstract}

\section{Introduction}

Indole alkaloids play a very important role in the chemistry of natural products and are especially recognized for their use in clinical medicine as an adjunct to anesthetics. The finding of several clinic uses has driven intense study of this class of substances, and many antiplasmodial $[1,2]$, cytotoxic [3], antibacterial [4], antifungal [5], spasmodic [6], hypotensive [7], and anti-inflammatory [8] properties have been related to indole alkaloids. Strictosidine (Figure 1) is a key glucomonoterpene indole alkaloid precursor of all indole monoterpene alkaloids. This crucial molecule, which originates from a reaction between tryptamine and the monoterpene glycoside secologanin, is found in several plant species [9-13] and was first isolated from Rhazya stricta [14]. Strictosidine has also been obtained in cell suspension cultures and under biomimetic conditions $[15,16]$.

Studies discussing the structure and stereochemistry of strictosidine [16-18] have compared its spectral data with those of similar structures, confirming that its C3 atom has the $\mathrm{S}$ configuration or $3 \alpha[\mathrm{S}]$. This configuration is identical to that of known monoterpene indole alkaloids, in disagreement with the proposal that vincoside was the precursor of indole alkaloids with $3 \beta[\mathrm{R}]$ configuration, as previously thought. Patthy-Lukáts et al. [19] studied the stereochemistry of strictosidine based on experimental NMR analysis, determining its spatial configuration. However, there are no X-ray studies because this molecule has not been obtained yet in crystalline 


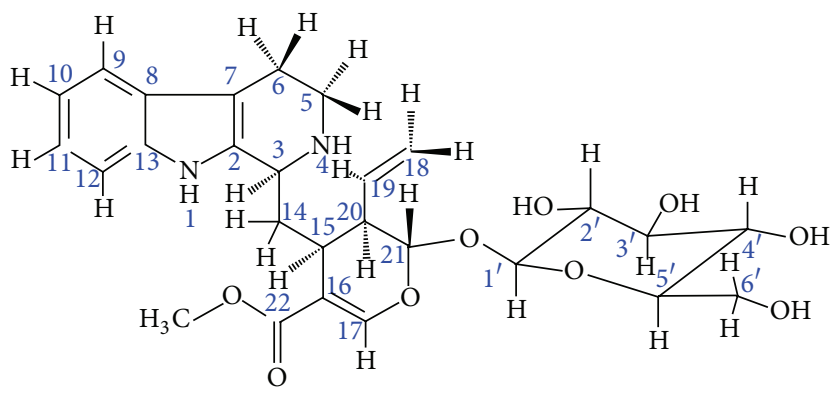

(a)

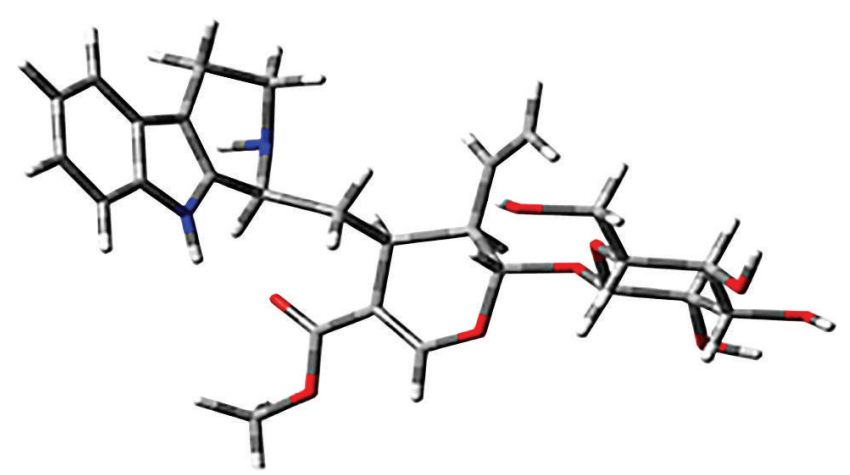

(b)

FIGURE 1: Structure of strictosidine.

form [19] and no theoretical molecular modeling study that discusses the bond lengths and planar and dihedral angles was previously presented. The determination of the relationship between theoretical vibrational frequencies and experimental IR absorbance bands and between theoretical electronic transitions and experimental UV bands of strictosidine has not been investigated yet. Therefore, a detailed theoretical DFT and experimental investigation of the structure and spectral behavior of this molecule, providing a comprehensive description of strictosidine, have been reported. Initially, the alkaloid has been isolated from Strychnos amazonica and the molecule was characterized by NMR $\left({ }^{1} \mathrm{H}\right.$, HSQC, and HMBC), MS (ESI-MS/MS), UV, and FTIR. The theoretical data (optimized geometry, UV, IV, MEP, and NBO calculations) were compared with the experimental data to answer questions regarding structure, electronic transitions involved in the UV spectrum, vibrational assignments, and other physical properties of strictosidine.

\section{Experimental Section}

2.1. General Procedures. Nuclear magnetic resonance (NMR) spectra were recorded on a Bruker 600 AVANCE spectrometer with 12.4-Tesla magnetons at $295 \mathrm{~K}$ in deuteriomethanol containing $0.06 \% \mathrm{TMS}$ as an internal standard. The ESI-MS ${ }^{n}$ data were recorded on LQC fleet ion trap Thermo Scientific spectrometer equipped with an electrospray ionization (ESI) ion source in the positive mode with the following parameters: capillary voltage at $26 \mathrm{~V}$; spray voltage at $5 \mathrm{kV}$; tube lens offset at $100 \mathrm{~V}$; capillary temperature at $225^{\circ} \mathrm{C}$; auxiliary gas at 5\%; and sheet gas at $12 \%$. The UV data were recorded in methanol using a PDA Detector plus Finnigan Surveyor (Thermo Scientific). The FTIR data were recorded in $\mathrm{KBr}$ pellet technique (solid phase) using an ABB FTLA200.

2.2. Plant Material. The leaves of Strychnos amazonica were collected in the Adolpho Ducke Forest Reserve located $25 \mathrm{~km}$ from the city of Manaus $\left(2^{\circ} 56^{\prime} 01.0^{\prime \prime} \mathrm{S}, 59^{\circ} 57^{\prime} 45.8^{\prime \prime} \mathrm{W}\right)$, Amazonas, Brazil. The species was identified by the DNA barcoding technique, in which the distance matrices, which were calculated for $\mathrm{rcbL}$ and $\mathrm{rpoCl}$ and for the concatenated gene sequences $(\mathrm{rbcL}+\mathrm{rpoCl})$, showed null values of genetic divergence between the collected specimen and a voucher specimen of Strychnos amazonica (INPA 216208) deposited in the herbarium of the National Research Institute of Amazonas (INPA). The $\mathrm{rcbL}$ and $\mathrm{rpoCl}$ sequences were deposited in GenBank under accession numbers KJ764797 to KJ764819.

2.3. Isolation of Strictosidine. $30 \mathrm{~g}$ of leaf extract in methanol was submitted to a silica-gel column using hexane/ethyl acetate and ethyl acetate/methanol as the mobile phases. Of the 31 fractions obtained, fractions 10 to 16 showed the presence of an alkaloid. These fractions were pooled and submitted to an ESI-TI-MS analysis, which showed an ion peak at $m / z$ 531. CID analysis revealed fragments at $m / z 514$, $m / z 369$, and $m / z 356$, which are compatible with strictosidine [20]. This fraction was submitted to a silica-gel column using $100 \%$ ethyl acetate, 9:1 ethyl acetate/methanol, and 100\% methanol in succession, resulting in an amorphous brown solid $(20 \mathrm{mg})$ that appeared to be pure in CCD/Dragendorff and ESI-IT-MS analyses (with only one ion peak at $\mathrm{m} / z$ 531). Then, it was subjected to NMR ( $\mathrm{H}^{1}, \mathrm{HMBC}$, and HSQC), UV, and IR analysis for structural confirmation (see Table S1 and Figures S1, S2, and S3 in the Supplementary Material data available online at http://dx.doi.org/10.1155/2016/1752429).

2.4. Computational Methods. The theoretical quantum chemical calculations were performed using the Gaussian 03 W Program (Revision E.01) on the Debian Linux (5.0 version) platform on an Intel Quadcore $^{\mathrm{m} x}$ PC (8 GB RAM) [21]. The DFT approach was used to optimize the geometry using the $6-31 \mathrm{G}(\mathrm{d})$ and $6-311 \mathrm{G}++(2 \mathrm{~d}, \mathrm{p})$ basis sets and the B3LYP functional. The molecular geometries were fully optimized by the force gradient method using Berny's algorithm, and the potential energy surfaces were characterized using standard analytical harmonic vibrational analysis to confirm that the stationary points corresponded to the minima of the potential energy surfaces (no imaginary frequencies or negative eigenvalues were found). The theoretical ${ }^{3} J_{\mathrm{HH}}$ coupling constants were calculated using the NMR protocols implemented using the DFT B3 LYP 
6-31G(d) and 6-311++G(2d,p) basis sets in the Gaussian 03 software. These coupling constants were compared with the measured values that were experimentally obtained, showing RMSD values of $1.45 \mathrm{~Hz}$ for DFT B3LYP $6-31 \mathrm{G}(\mathrm{d})$ and $1.25 \mathrm{~Hz}$ for $6-311++\mathrm{G}(2 \mathrm{~d}, \mathrm{p})$. The UV spectra were calculated using the RTD-B3LYP-FC functional and $6-31 G(\mathrm{~d})$ and $6-311 G++(2 d, p)$ basis set $[22,23]$. The NBO values were obtained with NBO 3.1, as implemented in the Gaussian 03 package using the $6-31 \mathrm{G}(\mathrm{d})$ basis set and the B3LYP functional. The harmonic frequencies were calculated at the B3LYP/6-31G(d) level using the optimized structural parameters. The assignments of the calculated wavenumbers were aided by the animation option of the GaussView program, which gives a visual presentation of the vibrational modes [24]. The potential energy distribution (PED) was calculated with the help of the VEDA4 software package [25].

\section{Results and Discussion}

3.1. Geometry Optimization. Because no crystallographic data for strictosidine are available, the geometry optimization data, which were calculated using the B3LYP/6-31G(d) and B3LYP/6-311++G(2d,p) basis set, were compared with the Xray data for similar structures [26-29]. Due to the similarity of the data obtained from both basis sets (Table 1), the discussion that follows is based on the B3LYP 6-31G(d) values but should also apply to B3LYP 6-311++G(2d,p).

Initially, the bond lengths indicated a small distortion in the pentacyclic tryptophan ring, showing a greater distance for the C7-C8 (1.44 $\AA$ ) and C8-C13 (1.42 $\AA$ ) bonds compared to the N1-C2, C2-C7, and C13-N1 bonds. Significant distortions were observed in the second six-membered ring of the tryptophan portion, which was distinct for all connections. Similar distortions were observed in the dihydropyran ring: $1.52 \AA$ (C15-C16), $1.35 \AA$ (C16-C17), $1.34 \AA$ (C7-O), $1.53 \AA$ (C20-C21), and $1.56 \AA$ (C20-C15). These distortions resulted from the presence of double bonds and heteroatoms, which make these bonds shorter than the $\mathrm{C}-\mathrm{C}$ bonds.

Concerning the planar angles, the aromatic ring shows no large deformations, which was similar to the experimental data for previously analyzed indole alkaloids $[26,29]$. The planar angles were $118.78^{\circ}$ (C9-C8-C13), $119.16^{\circ}$ (C8-C9-C10), $121.06^{\circ}$ (C9-C10-C11), $121.17^{\circ}$ (C10-C11-C12), $117.62^{\circ}$ (C11-C12$\mathrm{C} 13)$, and $122.18^{\circ}$ (C8-C12-C13). The pentacyclic ring showed a nonangular uniformity except for the angles between N1C2-C7 (109.56 ${ }^{\circ}$ and C13-C2-N1 $\left(109.22^{\circ}\right)$.

${ }^{1} \mathrm{H}-{ }^{1} \mathrm{H}$ NMR coupling constants are highly sensitive to the dihedral angles of hydrogen atoms and both the configuration and conformation of a structure can be validated if there is agreement between the experimental and theoretical ${ }^{3} J_{\mathrm{HH}}$ values. The calculated initial dihedral angles for the hydrogen atoms in positions 5 and 6 of the third ring of the tryptophan portion were $162.78^{\circ}$ (with theoretical ${ }^{\mathrm{T}} J_{\mathrm{H} 5 \mathrm{a}-\mathrm{H} 6 \mathrm{~b}}=11.0 \mathrm{~Hz}$ ) and $46.76^{\circ}$ (theoretical ${ }^{\mathrm{T}} J_{\mathrm{H} 5 \mathrm{a}-\mathrm{H} 6 \mathrm{a}}=4.2 \mathrm{~Hz}$ ). These values were consistent with the experimentally measured values for coupling constants, ${ }^{\mathrm{E}} J_{\mathrm{H} 5 \mathrm{a}-\mathrm{H} 6 \mathrm{~b}}=11.9 \mathrm{~Hz}$ and ${ }^{\mathrm{E}} J_{\mathrm{H} 6 \mathrm{a}-\mathrm{H} 5 \mathrm{a}}=4.8 \mathrm{~Hz}$, revealing a pseudoaxial-axial relationship between hydrogen atoms $\mathrm{H} 5 \mathrm{a}-\mathrm{H} 6 \mathrm{~b}$ and an axial-equatorial relationship between $\mathrm{H} 5 \mathrm{a}$ and H6a. The obtained dihedral angles for hydrogen atoms of the C3-C14-C15 bridge also showed coupling constants values consistent with the experimental values: $172.28^{\circ}$ for $\mathrm{H} 3-\mathrm{H} 14$ proR with theoretical ${ }^{\mathrm{T}} J_{3-14 \mathrm{R}}=10.7$ (experimental $\left.{ }^{\mathrm{E}} J_{3-14 \mathrm{R}}=11.4 \mathrm{~Hz}\right),-72.41^{\circ}$ for H3-H14proS with ${ }^{\mathrm{T}} J_{14 \mathrm{~S}-3}=$ $2.8 \mathrm{~Hz}\left({ }^{\mathrm{E}} J_{14 \mathrm{~S}-3}=3.6 \mathrm{~Hz}\right)$, and $-87.53^{\circ}$ for H14proR-H15 with ${ }^{\mathrm{T}} J_{\mathrm{H} 14 \mathrm{R}-\mathrm{H} 15}=0.6 \mathrm{~Hz}\left({ }^{\mathrm{E}} J_{\mathrm{H} 14 \mathrm{R}-\mathrm{H} 15}=1.8 \mathrm{~Hz}\right)$. The conformation of the dihedral angles involving $\mathrm{H} 15-\mathrm{H} 20\left(-56.90^{\circ}\right), \mathrm{H} 20-$ $\mathrm{H} 21\left(-178.69^{\circ}\right)$, and $\mathrm{H} 19-\mathrm{H} 20\left(65.23^{\circ}\right)$ is also plausible given the respective experimental hydrogen coupling constants ${ }^{\mathrm{T}} J_{\mathrm{H} 15-\mathrm{H} 20}=4.4 \mathrm{~Hz}\left({ }^{\mathrm{E}} J=4.8 \mathrm{~Hz}\right),{ }^{\mathrm{T}} J_{\mathrm{H} 20-\mathrm{H} 21}=8.1$ $\left({ }^{\mathrm{E}} J=8.4 \mathrm{~Hz}\right)$, and ${ }^{\mathrm{T}} J_{\mathrm{H} 19-\mathrm{H} 20}=3.0 \mathrm{~Hz}\left({ }^{\mathrm{E}} J=3.0 \mathrm{~Hz}\right)$. The similarity between the modeled DFT structure (Figure 2) (with 15S, 20S, and 21S configuration) and the experimental spectroscopic NMR data complements the conformational arrangement study of strictosidine. The 15S, 20S, and $21 \mathrm{~S}$ configuration was reported in previous experimental Xray studies of strictosidine precursors [19, 28-30]. Finally, due to the consistency between the geometry calculated using the DFT B3LYP/6-31G(d) and B3LYP/6-31++G(2d,p) methods and the coupling constant values measured from the experimental ${ }^{1} \mathrm{H}$ spectrum, the conformation of the C21$\mathrm{O}-\mathrm{Cl}^{\prime}$ bridge (so far uncertain) was depicted with angles of $81.17^{\circ}$ and lengths of $2.65 \AA$ between $\mathrm{H} 21$ and $\mathrm{H1}^{\prime}$ (Figure 2). This depiction is consistent with the NOESY data provided by Patthy-Lukáts et al. [19]. Other interactions between segments found in the NOESY data are justified by the calculated distances between the hydrogen atoms as follows:

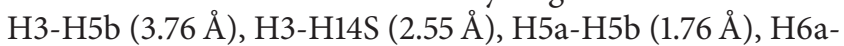
H6b (1.76 $\AA), H 9-H 10 ~(2.48 \AA), H 10-11$ (2.477 $\AA), H 11-H 12$

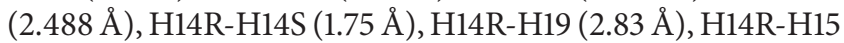
(2.66 $\AA), \mathrm{H} 14 \mathrm{~S}-\mathrm{H} 21$ (2.59 $\AA), \mathrm{H} 15-\mathrm{H} 20$ (2.41 $\AA), \mathrm{H} 18 \mathrm{Z}-\mathrm{H} 18 \mathrm{E}$ $(1.85 \AA), H 18 Z-H 20(3.57 \AA), H 18 E-H 19$ (2.40 $)$, and H20H19 (2.52 $\AA$ ) (for information about Mulliken charges and natural bond analysis, see Tables S2 and S3 in Supplementary Material data).

3.2. UV Analysis. The electronic spectrum of the molecule in a methanol solution was compared with the calculated spectrum (in the gas phase) at time dependent density functional using the B3LYP 6-31G(d) and B3LYP 6-311G++(2d,p) basis sets, as Figure 3 shows. The bands located at 222 and $272 \mathrm{~nm}$ could be experimentally observed and were in agreement with the presence of chromophores. Because strictosidine is an aromatic compound, $\pi \rightarrow \pi^{*}$ transitions were involved but the presence of conjugations in the pentacyclic ring of the tryptophan portion and in the $\beta$-alkoxyacrylate group suggested that $n \rightarrow \pi^{*}$ transitions also occurred. The theoretical calculations predicted an intense electronic transition of $5.8964 \mathrm{eV}$, with an oscillator strength $f=0.548$ at $210.27 \mathrm{~nm}$ for B3LYP 6-31G(d). For B3LYP 6-311++G(2d,p), an electronic transition of $5.62 \mathrm{eV}$ was predicted, with an oscillator strength $f=0.2714$ at $220.62 \mathrm{~nm}$. These results showed good agreement with the measured experimental data $(222 \mathrm{~nm})$ assigned to the $\pi \rightarrow \pi^{*}$ and $\pi \rightarrow \sigma^{*}$ transitions of the indole portion. The calculations also predicted a weaker electronic 
TABLE 1: Calculated geometrical parameters for strictosidine compared with the experimental data.

\begin{tabular}{|c|c|c|c|c|c|}
\hline Parameter & B3LYP 6-31G(d) & B3LYP 6-311++G(2d,p) & Molina et al. [27] & Dupont and Dideberg [26] & Lentz and Rossmann [29] \\
\hline \multicolumn{6}{|l|}{ Bond length } \\
\hline N1-C2 & 1.386 & 1.384 & 1.363 & 1.400 & \\
\hline $\mathrm{C} 2-\mathrm{C} 3$ & 1.507 & 1.506 & - & 1.488 & \\
\hline $\mathrm{C} 3-\mathrm{N} 4$ & 1.479 & 1.477 & - & 1.477 & \\
\hline N4-C5 & 1.472 & 1.473 & - & 1.482 & \\
\hline C5-C6 & 1.543 & 1.542 & - & 1.523 & \\
\hline C6-C7 & 1.501 & 1.501 & - & 1.490 & \\
\hline $\mathrm{C} 7-\mathrm{C} 2$ & 1.375 & 1.375 & 1.442 & 1.429 & \\
\hline $\mathrm{C} 7-\mathrm{C} 8$ & 1.439 & 1.439 & 1.457 & 1.425 & \\
\hline $\mathrm{C} 8-\mathrm{C} 9$ & 1.406 & 1.407 & - & 1.432 & \\
\hline $\mathrm{C} 8-\mathrm{C} 13$ & 1.427 & 1.426 & - & 1.406 & \\
\hline C9-C10 & 1.392 & 1.391 & - & 1.432 & \\
\hline C10-C11 & 1.411 & 1.410 & - & 1.377 & \\
\hline $\mathrm{C} 11-\mathrm{C} 12$ & 1.393 & 1.392 & - & 1.346 & \\
\hline $\mathrm{C} 12-\mathrm{C} 13$ & 1.399 & 1.398 & & 1.409 & \\
\hline C13-N1 & 1.381 & 1.381 & 1.406 & 1.379 & \\
\hline C14-C3 & 1.548 & 1.548 & - & 1.541 & \\
\hline C14-C15 & 1.552 & 1.562 & - & & 1.62 \\
\hline $\mathrm{C} 15-\mathrm{C} 16$ & 1.515 & 1.520 & - & & 1.48 \\
\hline C16-C17 & 1.350 & 1.350 & - & & $1.60^{*}$ \\
\hline C18-C19 & 1.335 & 1.334 & - & & $1.51^{*}$ \\
\hline C19-C20 & 1.512 & 1.513 & - & & 1.60 \\
\hline C20-C21 & 1.526 & 1.526 & - & & 1.50 \\
\hline $\mathrm{C} 21-\mathrm{O}$ & 1.401 & 1.403 & - & & 1.43 \\
\hline $\mathrm{C} 22-\mathrm{C} 16$ & 1.469 & 1.471 & - & & 1.60 \\
\hline $\mathrm{C} 23-\mathrm{O}$ & 1.437 & 1.441 & - & & 1.49 \\
\hline $\mathrm{Cl}^{\prime}-\mathrm{O}$ & 1.403 & 1.401 & - & & 1.42 \\
\hline $\mathrm{Cl}^{\prime}-\mathrm{C} 2^{\prime}$ & 1.528 & 1.526 & - & & 1.52 \\
\hline $\mathrm{C} 2^{\prime}-\mathrm{C} 3^{\prime}$ & 1.528 & 1.527 & - & & 1.51 \\
\hline $\mathrm{C} 3^{\prime}-\mathrm{C} 4^{\prime}$ & 1.527 & 1.528 & - & & 1.55 \\
\hline $\mathrm{C} 4^{\prime}-\mathrm{C} 5^{\prime}$ & 1.537 & 1.537 & - & & 1.52 \\
\hline $\mathrm{C} 5^{\prime}-\mathrm{C} 6^{\prime}$ & 1.523 & 1.522 & & & 1.52 \\
\hline $\mathrm{C}^{\prime}-\mathrm{O}$ & 1.438 & 1.442 & - & & 1.45 \\
\hline \multicolumn{6}{|l|}{ Bond angle } \\
\hline N1-C2-C7 & 109.570 & 109.562 & 108.7 & 110.5 & \\
\hline C2-C7-C8 & 107.063 & 107.071 & 105.7 & 107.0 & \\
\hline C7-C8-C13 & 106.793 & 106.792 & 107.5 & 107.2 & \\
\hline C8-C13-N1 & 107.347 & 107.343 & - & 108.0 & \\
\hline C13-N1-C2 & 109.221 & 109.221 & - & 107.3 & \\
\hline $\mathrm{C} 2-\mathrm{C} 3-\mathrm{N} 4$ & 110.742 & 110.742 & - & 106.6 & \\
\hline $\mathrm{C} 3-\mathrm{N} 4-\mathrm{C} 5$ & 114.580 & 114.582 & - & 112.6 & \\
\hline N4-C5-C6 & 114.370 & 114.370 & - & 110.1 & \\
\hline C5-C6-C7 & 108.976 & 108.976 & - & 109.4 & \\
\hline C6-C7-C2 & 121.873 & 121.881 & 128.9 & 122.1 & \\
\hline C7-C2-C3 & 125.545 & 125.546 & 107.9 & 126.2 & \\
\hline $\mathrm{C} 13-\mathrm{C} 8-\mathrm{C} 9$ & 118.786 & 118.771 & - & 119.7 & \\
\hline
\end{tabular}


TABLE 1: Continued.

\begin{tabular}{|c|c|c|c|c|c|}
\hline Parameter & B3LYP 6-31G(d) & B3LYP 6-311++G(2d,p) & Molina et al. [27] & Dupont and Dideberg [26] & Lentz and Rossmann [29] \\
\hline C8-C9-C10 & 119.165 & 119.172 & - & 115.3 & \\
\hline C9-C10-C11 & 121.057 & 121.052 & - & 122.7 & \\
\hline $\mathrm{C} 10-\mathrm{C} 11-\mathrm{C} 12$ & 121.177 & 121.181 & - & 122.2 & \\
\hline C11-C12-C13 & 117.626 & 117.625 & - & 117.6 & \\
\hline $\mathrm{C} 12-\mathrm{C} 13-\mathrm{C} 8$ & 122.186 & 122.186 & - & 122.4 & \\
\hline C2-C3-C14 & 111.904 & 111.903 & - & 110.8 & \\
\hline N4-C3-C14 & 110.456 & 110.456 & - & 116.9 & \\
\hline C3-C14-C15 & 113.558 & 113.562 & - & 112.7 & \\
\hline $\mathrm{C} 15-\mathrm{C} 16-\mathrm{C} 20$ & 112.883 & 112.883 & - & - & \\
\hline $\mathrm{C} 15-\mathrm{C} 16-\mathrm{C} 17$ & 112.915 & 112.914 & - & - & 107 \\
\hline $\mathrm{C} 16-\mathrm{C} 17-\mathrm{O}$ & 125.412 & 125.420 & - & - & 110 \\
\hline $\mathrm{C} 17-\mathrm{O}-\mathrm{C} 21$ & 119.937 & 119.941 & - & - & 121 \\
\hline C18-C19-C20 & 129.038 & 129.038 & - & - & 101 \\
\hline $\mathrm{C} 16-\mathrm{C} 22-\mathrm{O}$ & 113.414 & 113.415 & - & - & 111 \\
\hline $\mathrm{CH} 3-\mathrm{O}-\mathrm{C} 22$ & 115.912 & 115.912 & - & - & 116 \\
\hline $\mathrm{C} 21-\mathrm{O}-\mathrm{Cl}^{\prime}$ & 115.516 & 115.516 & - & - & 114 \\
\hline $\mathrm{O}-\mathrm{Cl}^{\prime}-\mathrm{C} 2^{\prime}$ & 108.278 & 108.278 & - & - & 106 \\
\hline $\mathrm{Cl}^{\prime}-\mathrm{C} 2^{\prime}-\mathrm{C} 3^{\prime}$ & 109.237 & 109.237 & - & - & 106 \\
\hline $\mathrm{C} 2^{\prime}-\mathrm{C} 3^{\prime}-\mathrm{C} 4^{\prime}$ & 111.945 & 111.945 & & & 110 \\
\hline $\mathrm{C} 3^{\prime}-\mathrm{C} 4^{\prime}-\mathrm{C} 5^{\prime}$ & 109.024 & 109.024 & - & - & 105 \\
\hline $\mathrm{C} 4^{\prime}-\mathrm{C} 5^{\prime}-\mathrm{O}$ & 108.796 & 108.795 & - & - & 106 \\
\hline $\mathrm{C}^{\prime}-\mathrm{O}-\mathrm{Cl}^{\prime}$ & 114.025 & 114.027 & - & - & 108 \\
\hline
\end{tabular}

${ }^{*}$ Corresponding to single bonds due to the crystallization process of loganin in loganin penta-acetate monomethyl ether bromide.

transition at $265.72 \mathrm{~nm}(4.66 \mathrm{eV})$ for B3LYP $6-31 \mathrm{G}(\mathrm{d})$ and at $278.26 \mathrm{~nm}(4.45 \mathrm{eV})$ for B3LYP $6-311++\mathrm{G}(2 \mathrm{~d}, \mathrm{p})$, which were equivalent to the band at $272 \mathrm{~nm}$ in the experimental spectrum. These values were assigned to the sum of the $n \rightarrow$ $\pi^{*}$ and $\pi \rightarrow \pi^{*}$ transitions of the indole and $\beta$-alkoxyacrylate groups.

The highest occupied molecular orbitals (HOMO) and the lowest-lying unoccupied molecular orbitals (LUMO), also called frontier molecular orbitals (FMOs), play an important role in many properties of a compound as well as in its quantum chemistry and UV-Vis spectra. The energy gap between the HOMO and LUMO energies is the basis for the chemical stability and reactivity of a molecule. The quantum bonding features of strictosidine are depicted by a plot of the HOMO, HOMO-1, LUMO, and LUMO-1 in Figure 4. In the UV-Vis spectrum, the two maximum calculated absorption wavelengths corresponded to the contributions of the electronic transitions from $\mathrm{HOMO} \rightarrow \mathrm{LUMO}+4$ (50.7\%) and $\mathrm{HOMO}-1 \rightarrow \mathrm{LUMO}+1$ (23.74\%) for $210 \mathrm{~nm}$ and HOMO $\rightarrow$ LUMO+1 (89.8\%) for $265 \mathrm{~nm}$ in B3LYP 6-31G(d). In B3LYP 6-311G++(2d,p), the wavelengths corresponded to $\mathrm{HOMO} \rightarrow \mathrm{LUMO}+16$ (26\%), HOMO $\rightarrow \mathrm{LUMO}+19$ (14\%), and $\mathrm{HOMO} \rightarrow \mathrm{LUMO}+18(5.7 \%)$ for $220.6 \mathrm{~nm}$ and $\mathrm{HOMO}$ $\rightarrow \mathrm{LUMO}+2$ (19\%) and $\mathrm{HOMO} \rightarrow \mathrm{LUMO}+3$ (70.81\%) for $278.3 \mathrm{~nm}$. It is clear from Figure 5 and Figures S5 and S6 (see Supplementary Information) that the major transitions were restricted to the indolic portion because the HOMO, HOMO-1, and LUMO+1 are located in this region and only the LUMO is located in the $\beta$-alkoxyacrylate group. Transitions involving the LUMO contribute minimally to the absorption wavelengths $(\lambda)$ of strictosidine, showing that the transitions in the $\beta$-alkoxyacrylate group have no influence, in disagreement with the ancient proposal that $\beta$ alkoxyacrylate group influences strictosidine UV spectrum [14]. This prediction was proven by the similarity of the experimental spectrum of strictosidine to the spectra of several other indole alkaloids that lack alkoxyacrylate groups [31].

3.3. Global and Local Reactive Descriptors. The energy gap between the HOMO and LUMO is very important for determining the electrical properties, kinetic stability, optical polarizability, and chemical reactivity descriptors, such as hardness and softness, of a molecule.

The concept of hardness $(\eta)$ and softness is related to a compound's reactivity and is a property that measures the extent of chemical reactivity to which the addition of a charge stabilizes the system. The chemical potential $(\mu)$ provides a global reactivity index and is related to charge transfer from a system of higher chemical potential to one of lower chemical potential. Electronegativity $(\chi)$ is the power to attract electrons and is directly related to all the previously mentioned properties. All these properties are defined as follows $[32,33]$ :

$$
\begin{aligned}
& \eta=\frac{1}{2}\left(\frac{\partial_{2} E}{\partial N_{2}}\right) V_{(r)}=\frac{1}{2}\left(\frac{\partial_{\mu}}{\partial N}\right) V_{(r)}, \\
& \mu=\left(\frac{\partial E}{\partial N}\right) V_{(r)}, \\
& \chi=-\mu=-\left(\frac{\partial E}{\partial N}\right) V_{(r)},
\end{aligned}
$$




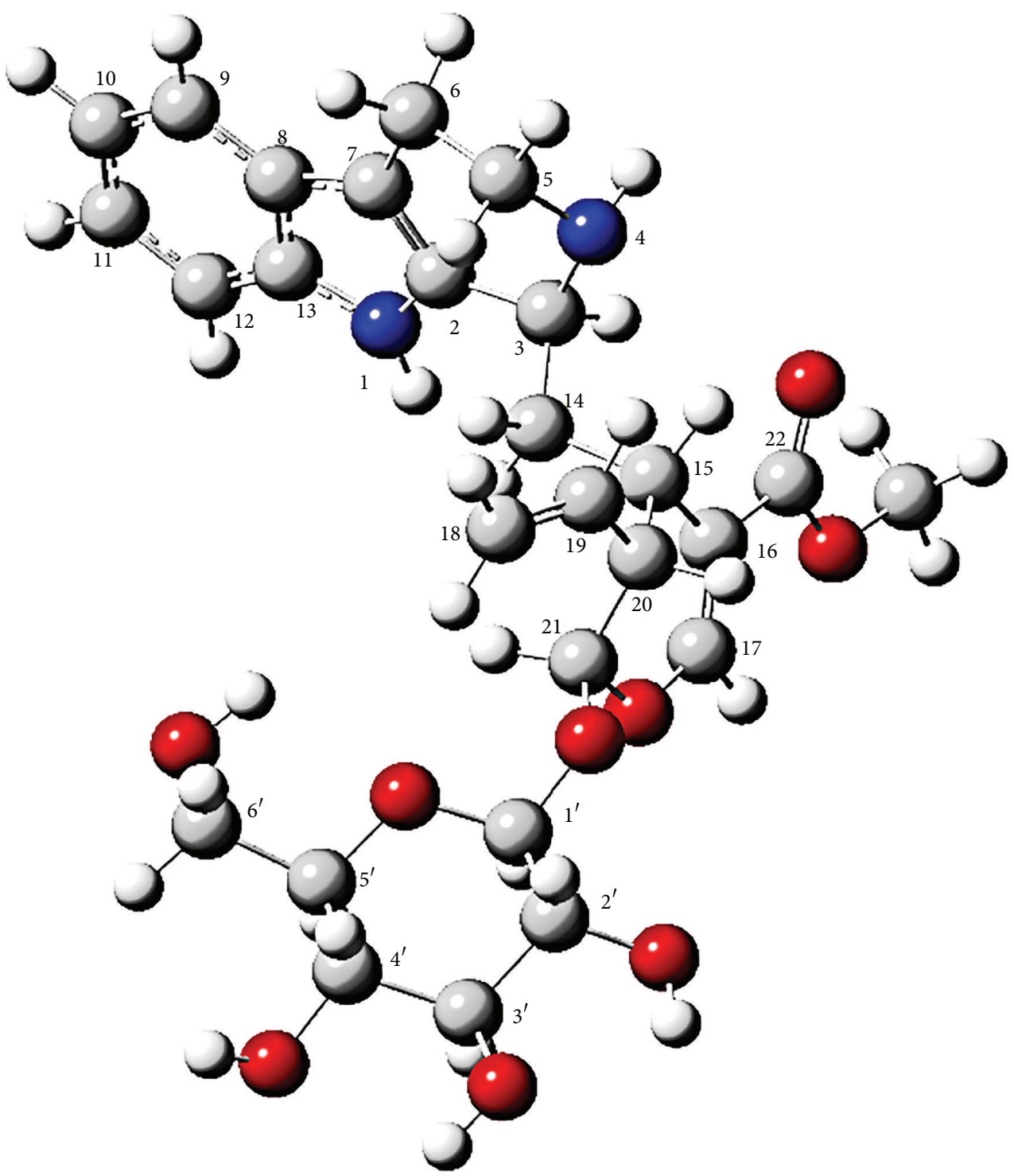

FIgURE 2: The optimized geometry of strictosidine with the scheme of atom numbering.

where $E$ and $V_{(r)}$ are the electronic energy and the external potential of an $N$-electron, respectively. Based on Koopmans theorem for closed-shell molecules, these global chemical reactivity descriptors can be simplified and defined as follows:

$$
\begin{aligned}
& \eta=\frac{(I-A)}{2}, \\
& \mu=\frac{-(I+A)}{2}, \\
& \chi=\frac{(I+A)}{2},
\end{aligned}
$$

where $A$ is the ionization potential and $I$ is the electron affinity of the molecule. The ionization energy and electron affinity are obtained from the HOMO and LUMO energies as $I=-E_{\mathrm{HOMO}}$ and $A=-E_{\mathrm{LUMO}}$. In terms of chemical hardness, a large HOMO-LUMO gap indicates a hard molecule and is related to more stable molecules, whereas a small gap indicates a soft molecule and is related to a more reactive molecule.

Another important descriptor is the electrophilicity index $(\omega)$, a global maximum reactivity index that is similar to chemical hardness and chemical potential. The electrophilicity index measures the global electrophilic nature of a molecule and was proposed by Parr et al. $[34,35]$ as a measure of energy lowering due to charge transfer. The electrophilicity index is defined as follows:

$$
\omega=\left(\frac{\mu^{2}}{2 \eta}\right) .
$$

This scale permits the classification of organic molecules as strong, $\omega>1.5 \mathrm{eV}$, moderate, $0.8<\omega<1.5 \mathrm{eV}$, and marginal, $\omega<0.8 \mathrm{eV}$, electrophiles. On the other hand, there 


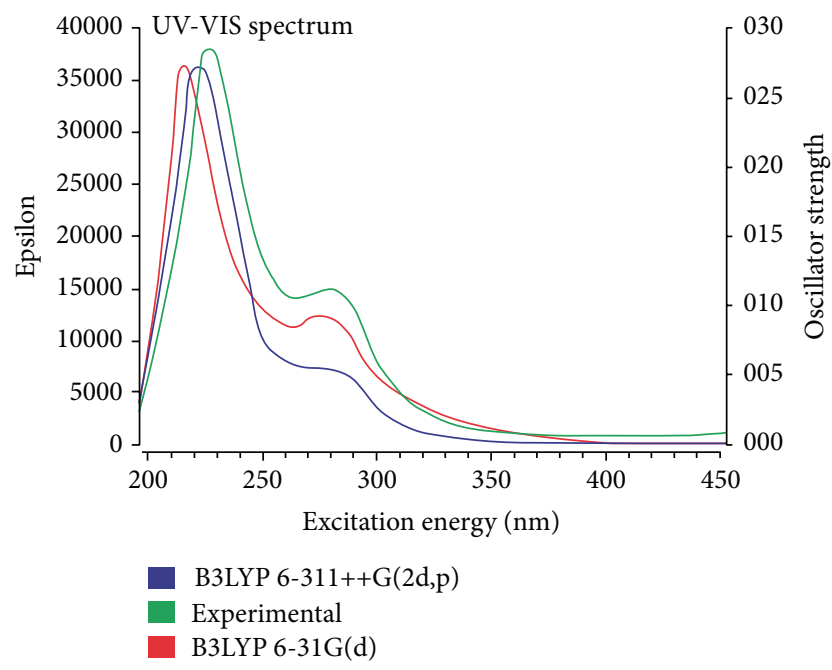

FIGURE 3: Experimental and theoretical ultraviolet-visible spectra of strictosidine in methanol.

is a good correlation in the inverse of the electrophilicity $(1 / \omega)$; thus, molecules located at the bottom of the electrophilicity scale are classified as marginal electrophiles, corresponding with good nucleophiles [36]. However, when the molecule bears more than one functional group with opposite electrical charge, its nucleophilic character cannot be straightforwardly associated with the inverse of the electrophilicity. Thus, the nucleophilicity index $(N)$ appears as a different descriptor which gives more information about nucleophilicity and is defined as follows [37]:

$$
N=E_{\mathrm{HOMO}}-E_{\mathrm{HOMO}(\mathrm{TCE})},
$$

where tetracyanoethylene (TCE) is taken as reference. All these properties were calculated using these equations for strictosidine in methanol through B3LYP/6-31G(d) and $B 3 L Y P / 6-311++G(2 d, p)$ basis sets and their values are shown in Table 2. Both HOMO and LUMO are bonding orbitals, resulting in a low excitation energy for strictosidine. The excitation energies, which were calculated as $4.451 \mathrm{eV}$ for $6-31 \mathrm{G}(\mathrm{d})$ and $4.408 \mathrm{eV}$ for $6-311++\mathrm{G}(2 \mathrm{~d}, \mathrm{p})$, reflect the low hardness value (2.22) showing strictosidine as a soft molecule with high polarizability. Electronegativity and electrophilicity values of strictosidine indicate that this molecule has significative attractive electron power acting as an electrophile and in addition to its polarization becomes very reactive since the electrons are farther from the nucleus; however, the nucleophilicity index value indicates that strictosidine is a strong nucleophile too. Such characteristic is justified because strictosidine is a large molecule that has many reactive groups with different potentials which forms small polarized points over its surface (as discussed in Section 3.6), which makes strictosidine a versatile molecule in view of the variety of alkaloids which it forms through intramolecular reactions with groups acting as nucleophiles and others as electrophiles [10]. On the other hand, the calculated chemical potential values, -3.06 for B3LYP/6-31G(d) and -3.40 for B3LYP/6-311++G(2d,p),
TABLE 2: Calculated energy values for strictosidine in methanol using B3LYP/6-31G(d) and B3LYP/6-311++G(2d,p).

\begin{tabular}{lcc}
\hline Basis set & B3LYP/6-31G(d) & B3LYP/6-311++G(2d,p) \\
\hline Energy (a.u.) & -1835.80 & -1836.39 \\
Dipole moment & 5.30 Debye & 5.50 Debye \\
$E_{\text {HOMO }}(\mathrm{eV})$ & -5.28 & -5.60 \\
$E_{\text {LUMO }}(\mathrm{eV})$ & -0.83 & -1.19 \\
$E_{\text {HOMO-LUMO }}(\mathrm{eV})$ & 4.45 & 4.40 \\
$E_{\text {HOMO-1 }}(\mathrm{eV})$ & -5.89 & -6.20 \\
$E_{\text {LUMO+1 }}(\mathrm{eV})$ & -0.18 & -0.62 \\
$E_{(\text {HOMO-1)-(LUMO+1) }}(\mathrm{eV})$ & 5.71 & 6.80 \\
Hardness $(\eta)$ & 2.22 & 2.20 \\
Chemical potential $(\mu)$ & -3.06 & -3.40 \\
Electronegativity $(\chi)$ & 3.06 & 3.40 \\
Electrophilicity index $(\omega)$ & 2.11 & 2.63 \\
Nucleophilicity index $(N)$ & 5.82 & 5.91 \\
\hline
\end{tabular}

reveal certain stability, indicating that it does not decompose spontaneously; that is, strictosidine molecule is reactive but does not tend to degrade into the components that formed it.

3.4. Tandem Mass Identification. The tandem mass spectra of protonated strictosidine (Figure S4 in Supplementary Data) of $\mathrm{m} / z 531$ showed major fragment ions of $\mathrm{m} / z 514,369$, and 352. The ion of $m / z 514[\mathrm{M}+\mathrm{H}-17 \mathrm{Da}]$ originated by loss of the $\mathrm{NH}_{3}$ group from the tryptophane portion in a manner that was similar to the fragmentation of aporphine alkaloids (Pathway A) [38]. The ESI-MS ${ }^{3}$ of this ion generated fragment ions of $m / z 352[\mathrm{M}+\mathrm{H}-162 \mathrm{Da}]$ due to the hydrogen rearrangement in the glycoside followed by heterolytic cleavage of the $\mathrm{C} 21-\mathrm{O}-\mathrm{Cl}^{\prime}$ bridge (Pathway C). The fragment ion of $m / z 369$ [M $+\mathrm{H}-162 \mathrm{Da}$ ] possibly arose directly from the heterolytic breakage of the glycoside portion of strictosidine via the cleavage of the $\mathrm{C} 21-\mathrm{O}-\mathrm{Cl}^{\prime}$ bridge (Pathway B), which occurred through a similar mechanism to Pathway C. No fragment ions were observed in the $\mathrm{MS}^{3}$ spectrum of the ion of $\mathrm{m} / z$ 369. Guided by the ESI-MS ${ }^{2}$ and $\mathrm{MS}^{3}$ data, a fragmentation mechanism is proposed for protonated strictosidine in Figure 5.

3.5. NBO Study. An NBO analysis describes the Lewislike molecular bonding pattern of electron pairs (or of individual electrons in the open-shell case) in the optimally compact form of the molecule. More precisely, NBOs are orthonormal sets of localized "maximum occupancy" orbitals whose leading $N / 2$ members (or $N$ members in the open-shell case) give the most accurate possible Lewis-like description of the total $N$-electron density. The Lewis-type NBOs determine the localized natural Lewis structure (NLS) representation of the wave function, while the remaining "non-Lewis-type" NBOs complete the span of the basis and describe the residual "delocalization effects" (i.e., departures from a single localized Lewis structure). NBOs provide therefore a valence bond-type description of the wave function that is closely linked to classical Lewis structure concepts [39-42]. 


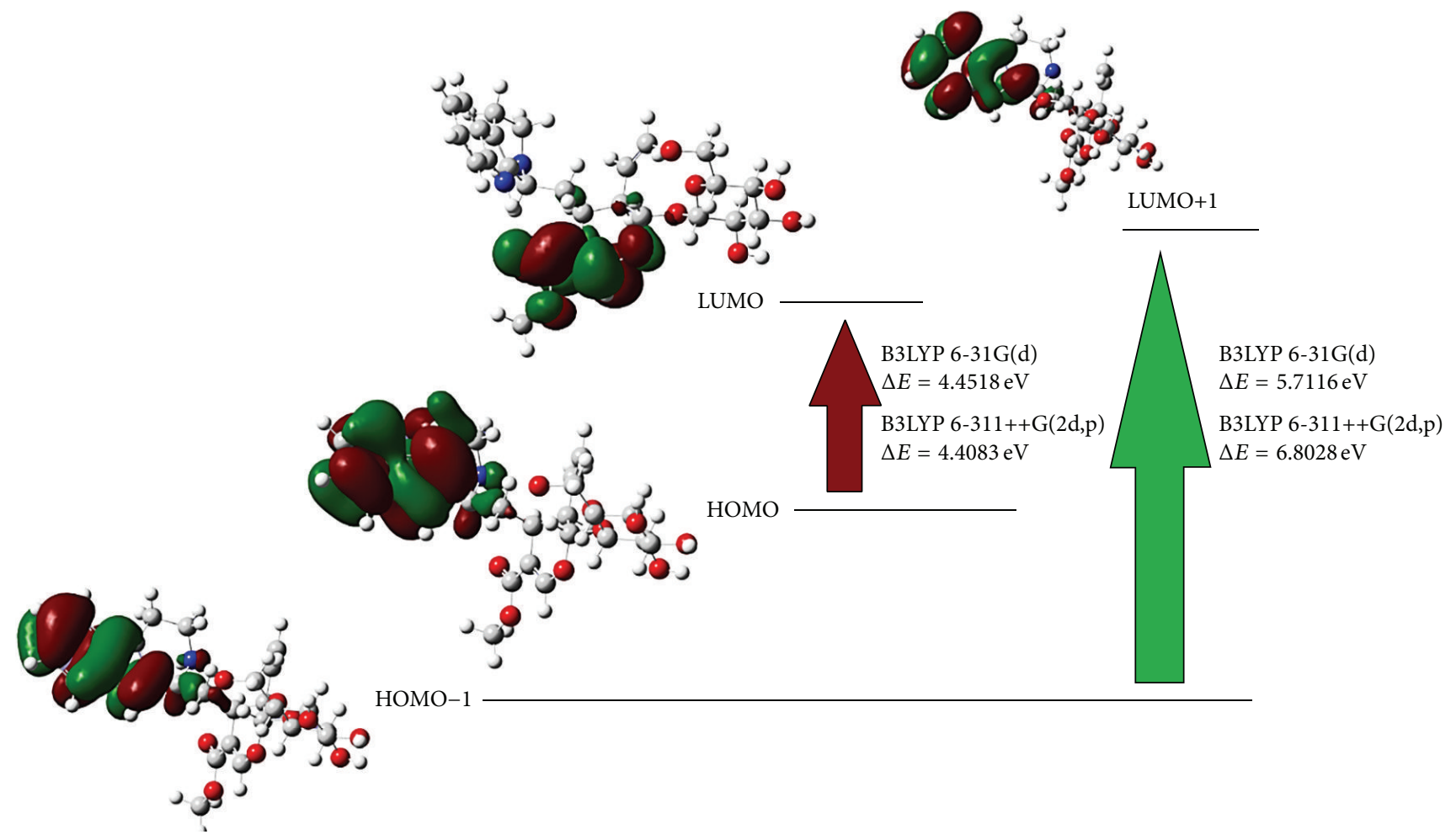

FIGURE 4: Frontier molecular orbitals of strictosidine.

TABLE 3: Electron population in Lewis and non-Lewis orbitals for strictosidine.

\begin{tabular}{lcc}
\hline Orbitals & Electrons & Percentage \\
\hline Core & 75.97 & $99.96 \%$ of 76 \\
Valence Lewis & 201.50 & $97.817 \%$ of 202 \\
Total Lewis & 277.47 & $98.39 \%$ of 282 \\
Valence non-Lewis & 4.02 & $1.43 \%$ of 282 \\
Rydberg non-Lewis & 0.50 & $0.17 \%$ of 282 \\
Total non-Lewis & 4.53 & $1.61 \%$ of 282 \\
\hline
\end{tabular}

NBO analysis is a helpful tool for understanding the delocalization of the electron density from the occupied Lewis-type (donor) NBOs to properly unoccupied nonLewis-type (acceptor) NBOs [43-47] within the molecule. This analysis uses the second-order perturbation energies $E^{(2)}$ [donor $(i) \rightarrow$ acceptor $(j)$ ] that involve the most important delocalization instances, which are given as follows:

$$
E^{(2)}=\Delta_{i j}=q_{i} \frac{F_{i j^{2}}}{\varepsilon_{j}-\varepsilon_{i}} \text {. }
$$

Table 3 shows more-detailed breakdown of the Lewis and non-Lewis occupancies, confirming the quality of the natural Lewis structure description. The total Lewis occupancy was $98.395 \%$ and the non-Lewis occupancy was $1.605 \%$. The NBO analysis revealed strong intramolecular interactions formed by the orbital overlaps between $\mathrm{C}-\mathrm{C}$ bonding and $\mathrm{C}$ $\mathrm{C}$ antibonding and by overlaps between the $\mathrm{N}$ and $\mathrm{O}$ lone pairs (LP) and $\mathrm{C}-\mathrm{C}$ antibonding. These interactions led to intramolecular electron-density transfer that caused the stabilization of the molecular system (Table 4). The intramolecular hyperconjugative interactions between $\mathrm{C} 2, \mathrm{C} 7, \mathrm{C} 8, \mathrm{C}$, $\mathrm{C} 10, \mathrm{C} 11, \mathrm{C} 12, \mathrm{C13}$, and $\mathrm{N} 1$ revealed strong stabilization of the indolic portion, principally by $\pi \rightarrow \pi^{*}$ interactions between $\mathrm{C} 11-\mathrm{C} 10 \rightarrow$ C8-C9 $(20.07 \mathrm{kcal} / \mathrm{mol}), \mathrm{C} 9-\mathrm{C} 8 \rightarrow \mathrm{C} 11-$ $\mathrm{C} 10(20.77 \mathrm{kcal} / \mathrm{mol}), \mathrm{C} 9-\mathrm{C} 8 \rightarrow \mathrm{C} 13-\mathrm{C} 12(20.01 \mathrm{kcal} / \mathrm{mol})$, and $\mathrm{C} 13-\mathrm{C} 12 \rightarrow \mathrm{C} 8-\mathrm{C} 9(19 \mathrm{kcal} / \mathrm{mol})$ and electron donation from LP(1) N1 to $\pi^{*}$ C2-C7 $(36.44 \mathrm{kcal} / \mathrm{mol})$ and $\pi^{*} \mathrm{C} 12$ $\mathrm{C} 13(40.91 \mathrm{kcal} / \mathrm{mol})$. Other hyperconjugative interactions, especially the donation of electron density from $\mathrm{LP}(2) \mathrm{O} 3$ to $\pi^{*} \mathrm{C} 16-\mathrm{C} 17(37.05 \mathrm{kcal} / \mathrm{mol}), \mathrm{LP}(1) \mathrm{O} 2$ to $\sigma^{*} \mathrm{C} 22-\mathrm{O} 1$ (32 kcal/mol), and $\mathrm{LP}(2) \mathrm{O} 1$ to $\pi^{*} \mathrm{C} 22-\mathrm{O} 2$, gave strong stabilization to the dihydropyran ring of strictosidine. In addition, the $\pi^{*} \rightarrow \pi^{*}$ interactions of C8-C9 $\rightarrow$ C7-C2 and $\mathrm{C} 21-\mathrm{O} 2 \rightarrow \mathrm{C} 16-\mathrm{C} 17$ provided enormous stabilization of $191.70 \mathrm{kcal} / \mathrm{mol}$ and $62.11 \mathrm{kcal} / \mathrm{mol}$, respectively. Table 4 provides all significant values for the hyperconjugative interactions given by the second-order perturbation theory.

A relationship between the ESI-IT-MS study and the stabilization caused by orbital overlap between bonds in the second-order perturbation theory could be established. The strongest stabilization energies for strictosidine involved hyperconjugative interactions in the indolic portion (aromatic and pentacyclic rings) and in the dihydropyran portion, explaining the small number of cleavages and the absence of breakages in the indolic portion and in the dihydropyran ring. In the fragmentation mechanism proposed in Figure 2, the most stable fragments arose from the heterolytic 


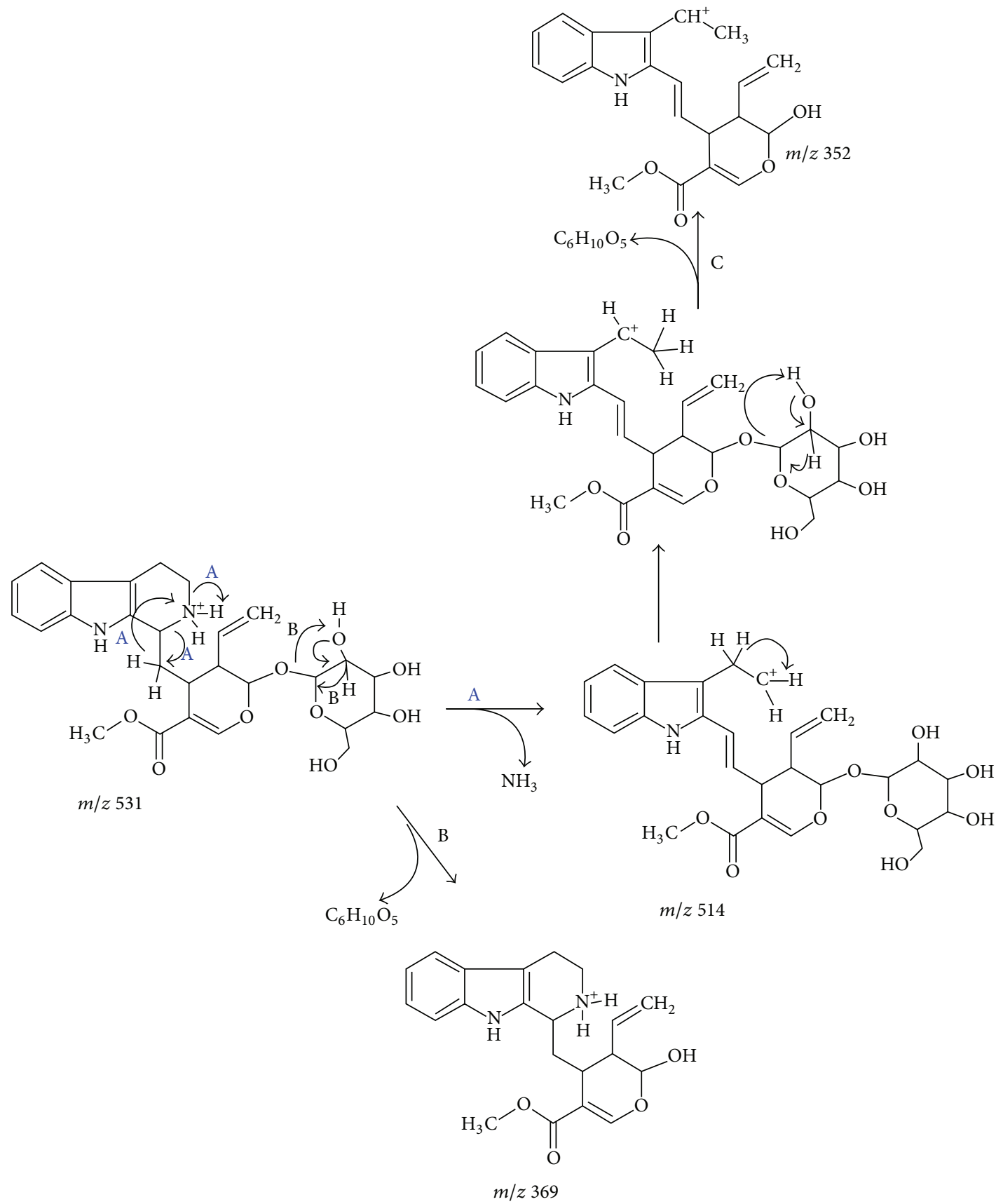

FIGURE 5: Mechanism proposed for the major fragmentation pathways of protonated strictosidine.

breakage of the O4-Cl', N4-C3, and N4-C5 bonds, which have the following weak hyperconjugative interactions: N4$\mathrm{C} 3 \rightarrow \mathrm{N} 2-\mathrm{C} 3\left(\sigma \rightarrow \sigma^{*}, 3.59 \mathrm{kcal} / \mathrm{mol}\right), \mathrm{C} 5-\mathrm{N} 4 \rightarrow \mathrm{C} 3\left(\sigma \rightarrow \sigma^{*}\right.$, $1.5 \mathrm{kcal} / \mathrm{mol}), \mathrm{N} 4-\mathrm{H} \rightarrow \mathrm{C} 5\left(\sigma \rightarrow \sigma^{*}, 1.68 \mathrm{kcal} / \mathrm{mol}\right), \mathrm{N} 4-$ $\mathrm{H} \rightarrow \mathrm{C} 5-\mathrm{H}\left(\sigma \rightarrow \sigma^{*}, 2.51 \mathrm{kcal} / \mathrm{mol}\right), \mathrm{O} 4-\mathrm{Cl}^{\prime} \rightarrow \mathrm{C} 20-\mathrm{C} 21$ $\left(\sigma \rightarrow \sigma^{*}, 1.46 \mathrm{kcal} / \mathrm{mol}\right)$, and $\mathrm{O} 3-\mathrm{C} 21 \rightarrow \mathrm{C} 21-\mathrm{O} 4(\sigma \rightarrow$ $\left.\sigma^{*}, 0.51 \mathrm{kcal} / \mathrm{mol}\right)$. These results showed that the NBO study complemented the mass fragmentation study.

3.6. Molecular Electrostatic Potential Surface. Figure 6 illustrates $3 \mathrm{D}$ plots of the molecular electrostatic potential (MEP) surface for the strictosidine molecule. An MEP is a plot of the electrostatic potential mapped onto the constant electron density surface and is used primarily for predicting sites and relative reactivities towards electrophilic and nucleophilic attacks. MEPs are used in studies of biological recognition and interactions between the same molecules (e.g., in forming clusters and crystal structures) or other molecules. MEPs also correlate and predict a wide range of macroscopic properties $[48,49]$. The color code of these maps ranges from -0.08 a.u. (deepest red) to 0.08 a.u. (deepest blue), where blue indicates a minimal concentration of electrons and red indicates a high density of electrons. 
TABLE 4: Selected second-order perturbation energies for strictosidine.

\begin{tabular}{|c|c|c|c|c|c|}
\hline Donor orbital $(i)$ & Type & Acceptor orbital $(j)$ & Type & $E_{(j)}-E_{(i)}$ a.u. & $E^{(2)}(\mathrm{kcal} / \mathrm{mol})$ \\
\hline \multirow{2}{*}{$\mathrm{C} 11-\mathrm{C} 10$} & \multirow{2}{*}{$\pi$} & $\mathrm{C} 9-\mathrm{C} 8$ & $\pi^{*}$ & 0.28 & 20.07 \\
\hline & & $\mathrm{C} 13-\mathrm{C} 12$ & $\pi^{*}$ & 0.27 & 18.90 \\
\hline \multirow{3}{*}{ C9-C8 } & \multirow{3}{*}{$\pi$} & $\mathrm{C} 11-\mathrm{C} 10$ & $\pi^{*}$ & 0.27 & 20.77 \\
\hline & & $\mathrm{C} 12-\mathrm{C} 13$ & $\pi^{*}$ & 0.27 & 20.01 \\
\hline & & $\mathrm{C} 7-\mathrm{C} 2$ & $\pi^{*}$ & 0.29 & 14.88 \\
\hline \multirow{2}{*}{$\mathrm{C} 13-\mathrm{C} 12$} & \multirow{2}{*}{$\pi$} & $\mathrm{C} 11-\mathrm{C} 10$ & $\pi^{*}$ & 0.28 & 21.04 \\
\hline & & C8-C9 & $\pi^{*}$ & 0.29 & 16.32 \\
\hline $\mathrm{C} 7-\mathrm{C} 2$ & $\pi$ & $\mathrm{C} 9-\mathrm{C} 8$ & $\pi^{*}$ & 0.29 & 19.71 \\
\hline $\mathrm{C} 16-\mathrm{C} 17$ & $\pi$ & $\mathrm{C} 22-\mathrm{O} 1$ & $\pi^{*}$ & 0.29 & 24.34 \\
\hline N1 & $\mathrm{LP}(1)$ & $\mathrm{C} 13-\mathrm{C} 12$ & $\pi^{*}$ & 0.29 & 40.91 \\
\hline N1 & $\mathrm{LP}(1)$ & C2-C7 & $\pi^{*}$ & 0.31 & 36.44 \\
\hline $\mathrm{O} 3$ & $\mathrm{LP}(2)$ & $\mathrm{C} 16-\mathrm{C} 17$ & $\pi^{*}$ & 0.36 & 37.05 \\
\hline $\mathrm{O} 4$ & $\mathrm{LP}(2)$ & $\mathrm{O} 3-\mathrm{C} 21$ & $\sigma^{*}$ & 0.56 & 15.13 \\
\hline O4 & $\mathrm{LP}(2)$ & $\mathrm{Cl}^{\prime}-\mathrm{O} 5$ & $\sigma^{*}$ & 0.60 & 13.48 \\
\hline $\mathrm{O} 2$ & $\mathrm{LP}(1)$ & C22 & $\mathrm{RY}^{*}$ & 1.55 & 14.52 \\
\hline $\mathrm{O} 2$ & $\mathrm{LP}(2)$ & $\mathrm{C} 16-\mathrm{C} 22$ & $\sigma^{*}$ & 0.72 & 16.43 \\
\hline $\mathrm{O} 2$ & $\mathrm{LP}(2)$ & $\mathrm{C} 22-\mathrm{O} 1$ & $\pi^{*}$ & 0.63 & 32.65 \\
\hline $\mathrm{O} 1$ & $\mathrm{LP}(2)$ & $\mathrm{C} 22-\mathrm{O} 2$ & $\pi^{*}$ & 0.32 & 47.44 \\
\hline $\mathrm{C} 8-\mathrm{C} 9$ & $\pi^{*}$ & C7-C2 & $\pi^{*}$ & 0.01 & 191.70 \\
\hline $\mathrm{C} 22-\mathrm{O} 2$ & $\pi^{*}$ & C16-C17 & $\pi^{*}$ & 0.03 & 62.11 \\
\hline
\end{tabular}
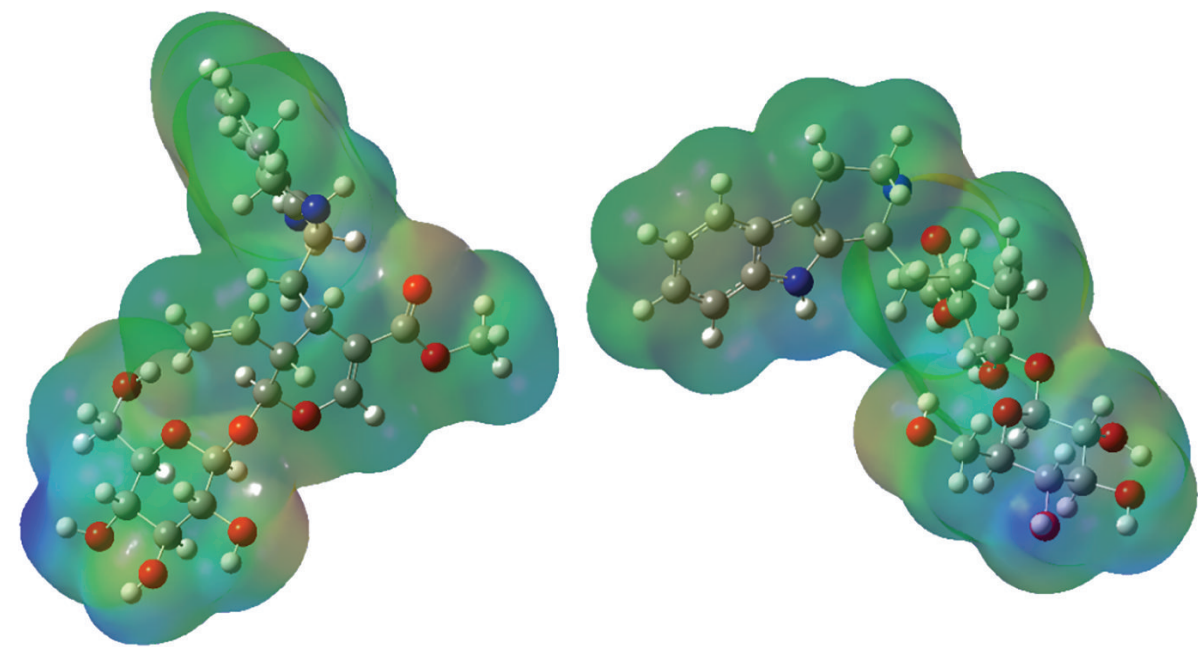

FIGURE 6: Molecular electrostatic potential maps (from two perspectives) for strictosidine calculated using the B3LYP/6-31G(d) basis set.

The MEPs for strictosidine indicated regions with positive potentials over $\mathrm{H1}$ (0.0627 a.u.) and over the hydrogen atom of the $\mathrm{OH}$ group in position $4^{\prime}$ (0.0862 a.u.). Regions with negative potentials were located over the aromatic ring $(-0.0429$ a.u.), over the carbonyl group O2 ( -0.0576 a.u.), between $\mathrm{O} 4$ and the $\mathrm{OH}$ group of $\mathrm{C}^{\prime}$ position $(-0.0643$ a.u. $)$, over $\mathrm{OH}$ on position $\mathrm{C6}^{\prime}$ ( -0.0471 a.u.), and over oxygen atom on $\mathrm{C} 4^{\prime}$ position (-0.0201 a.u.). The predominance of light green color region indicates great charge dispersion. Strictosidine is a large molecule with polarized points scattered over its surface which promotes various possible forms of intramolecular and intermolecular interaction (between strictosidine molecules); in addition, the nonflat shape hinders the chain interactions between strictosidine molecules which facilitate formation of a packed crystal.

3.7. IR Analysis. Figure 7 shows the experimental and theoretical IV spectra. The differences can be attributed to the fact that the theoretical DFT calculations were made for the molecule in the gas phase, whereas intermolecular interactions occur in solution. The assignment of the experimental bands to the normal modes of vibration was made using the optimized structure with the lowest potential energy, considering the potential energy distribution (PED) 


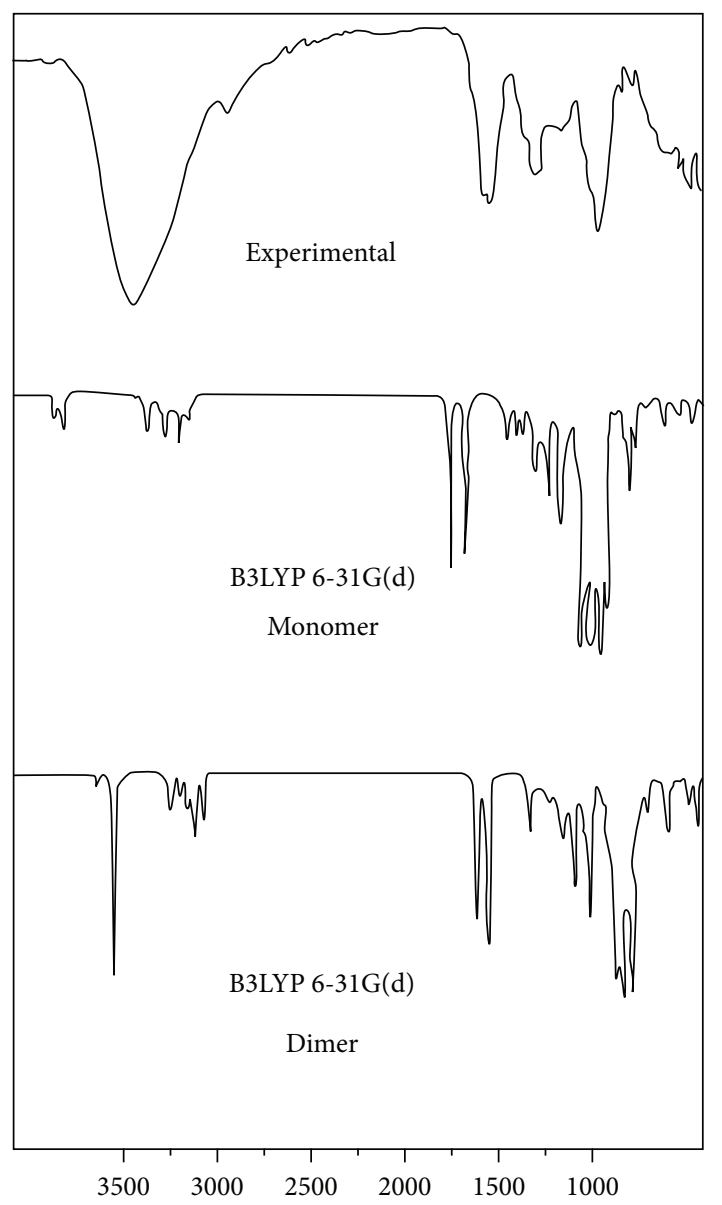

FIGURE 7: Experimental IR spectrum (top), theoretical B3LYP 631G(d) strictosidine monomer (middle), and theoretical B3LYP 6$31 \mathrm{G}(\mathrm{d})$ (bottom) strictosidine dimer IR spectra, in $\mathrm{cm}^{-1}$.

by using the B3LYP/6-31G(d) level. A total of 210 normal vibration modes were obtained but were compared with the experimental spectrum only between 400 and $4000 \mathrm{~cm}^{-1}$ (Table 5).

Modes between 3021 and $3640 \mathrm{~cm}^{-1}$ were related to the following vibrations: the strong $\mathrm{O}-\mathrm{H}$ stretching of the glycoside portion; the $\mathrm{H}-\mathrm{C}$ stretching of the aromatic ring; the $\mathrm{H}-\mathrm{C}$ stretching of dihydropyran ring; the $\mathrm{N} 4-\mathrm{H} 1$ and N1-H1 stretching; and the H3-C3, H5-C5, H6-C6, H14-C14, and H15-C15 stretching. The region from 2900 to $3000 \mathrm{~cm}^{-1}$ showed a strong band at $2932 \mathrm{~cm}^{-1}$ that was assigned to the symmetric $\mathrm{CH}_{2}$ stretching in $\mathrm{C} 6$.

The region between 1060 and $1700 \mathrm{~cm}^{-1}$ was related to the following vibrations: the $\mathrm{C}=\mathrm{O}$ stretching of $\mathrm{C} 22, \mathrm{C}=\mathrm{C}$ stretching modes of $\mathrm{C} 16=\mathrm{Cl}$, the H1-N1 bending mode, and the $\mathrm{CH}_{2}$ scissoring modes $\left(\mathrm{C}^{\prime}{ }^{\prime}\right.$ and $\left.\mathrm{C} 23\right)$ in $1400-$ $1690 \mathrm{~cm}^{-1}$; the $\mathrm{H}-\mathrm{C}$ bending of the glycoside portion and the dihydropyran ring in $1250-1399 \mathrm{~cm}^{-1}$; the O-C stretching of the glycoside portion between 1060 and $1211 \mathrm{~cm}^{-1}$.

The region between 600 and $1030 \mathrm{~cm}^{-1}$ was related to the $\mathrm{C}-\mathrm{C}$ stretching of $\mathrm{C} 10$ and $\mathrm{C} 11$, the $\mathrm{C}-\mathrm{O}$ and $\mathrm{C}-\mathrm{C}$ stretching of the glycosidic moiety, the $\mathrm{H}-\mathrm{N}$ bending of the $\mathrm{N} 4$ position (band at $891 \mathrm{~cm}^{-1}$ was noteworthy), the out-of-plane mode of C22 (at $763 \mathrm{~cm}^{-1}$ ), and the torsion modes of the entire structure.

The large differences from 3500 to $4000 \mathrm{~cm}^{-1}$ are related to the $\mathrm{H}-\mathrm{Nl}$ and $\mathrm{O}-\mathrm{H}$ stretching, which are indicative that the interactions between strictosidine molecules occur between the tryptophanic and glycosidic regions. These interactions make sense based on the electrostatic potential map (Figure 6), which showed greater polarization of these two regions relative to the entire molecule. The optimized geometry of a strictosidine dimer (Figure 8) showed stabilization due to the existence of intermolecular hydrogen bonds (N1-H1---O-C4' and $\left.\mathrm{C}^{\prime}-\mathrm{OH}---\mathrm{O} 2=\mathrm{C} 22\right)$ and the values assigned to the stretching of $\mathrm{O}-\mathrm{H}\left(3556.00 \mathrm{~cm}^{-1}\right)$ and $\mathrm{H}-\mathrm{N} 1$ $\left(3493.18 \mathrm{~cm}^{-1}\right)$ groups are closer to the experimental ones (3430 and $3390 \mathrm{~cm}^{-1}$ ). The value assigned to the stretching of carboline group in position C22 $\left(1690 \mathrm{~cm}^{-1}\right)$ shows to be closer to the experimental one in the dimer too $\left(1767 \mathrm{~cm}^{-1}\right.$ to the monomer and $1716 \mathrm{~cm}^{-1}$ to the dimer form), implying that the interaction between the carbonyl and $\mathrm{OH}$ is plausible and decreasing the stretching frequency oscillator related to $\mathrm{C}=\mathrm{O}$ bond. These interactions directly influenced the infrared spectrum by decreasing the stretching frequency oscillator related to these bonds, causing reduction in the wavelengths (see Figure 8) and in the RMSD values. For the monomer, the RMSD is $84.40 \mathrm{~cm}^{-1}$; for the dimer, the value is 46.41. Applying the empirical scaling factor of 0.9613 , the RMSD values feature a visible reduction, $66.33 \mathrm{~cm}^{-1}$ for monomer and $30.66 \mathrm{~cm}^{-1}$ for dimer.

\section{Conclusion}

The strictosidine alkaloid, which was isolated from Strychnos amazonica, was comprehensively characterized. The interatomic distances and angles proved to be plausible compared to the X-ray data for similar molecules. The similarity between the theoretical and experimental coupling constants values reveals that the theoretical hydrogen dihedral angles of the C14-C15-C20-C21-C19 positions are plausible, showing that the modeled structure justifies the experimental NMR data. The UV analysis was able to explain the similarity between the UV spectra of strictosidine and related indole alkaloids, showing that the transitions involving the indole moiety are energetically more significant and such characteristic can be used as a "fingerprint" for detecting indole alkaloids. The HOMO-LUMO gap is directly related to the reactivity of a compound reflecting the amount of important properties such as chemical hardness, electrophilicity, nucleophilicity index, and electronegativity. Strictosidine theoretically appears to be a nucleophile and electrophile that in addition to its polarizability behaves as a soft molecule. This indicates low charge states and faster reactions, which makes strictosidine a versatile molecule, justifying its high reactivity and its role as a precursor of indole alkaloids. The comparative IR studies revealed that interactions of strictosidine dimers (between the tryptophanic and glycosidic regions) influenced the infrared spectrum by decreasing the stretching frequency oscillator of the groups which forms hydrogen 


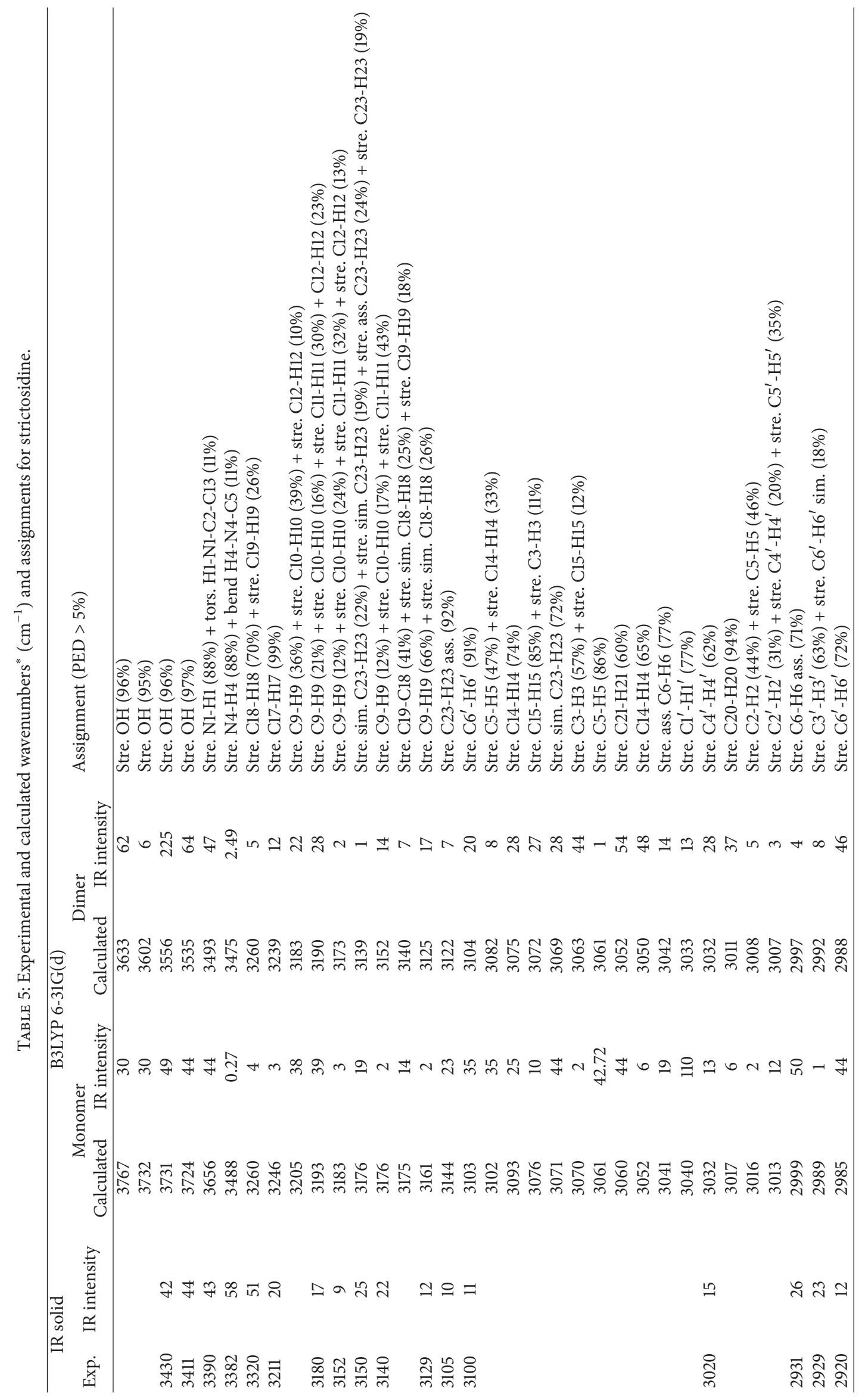




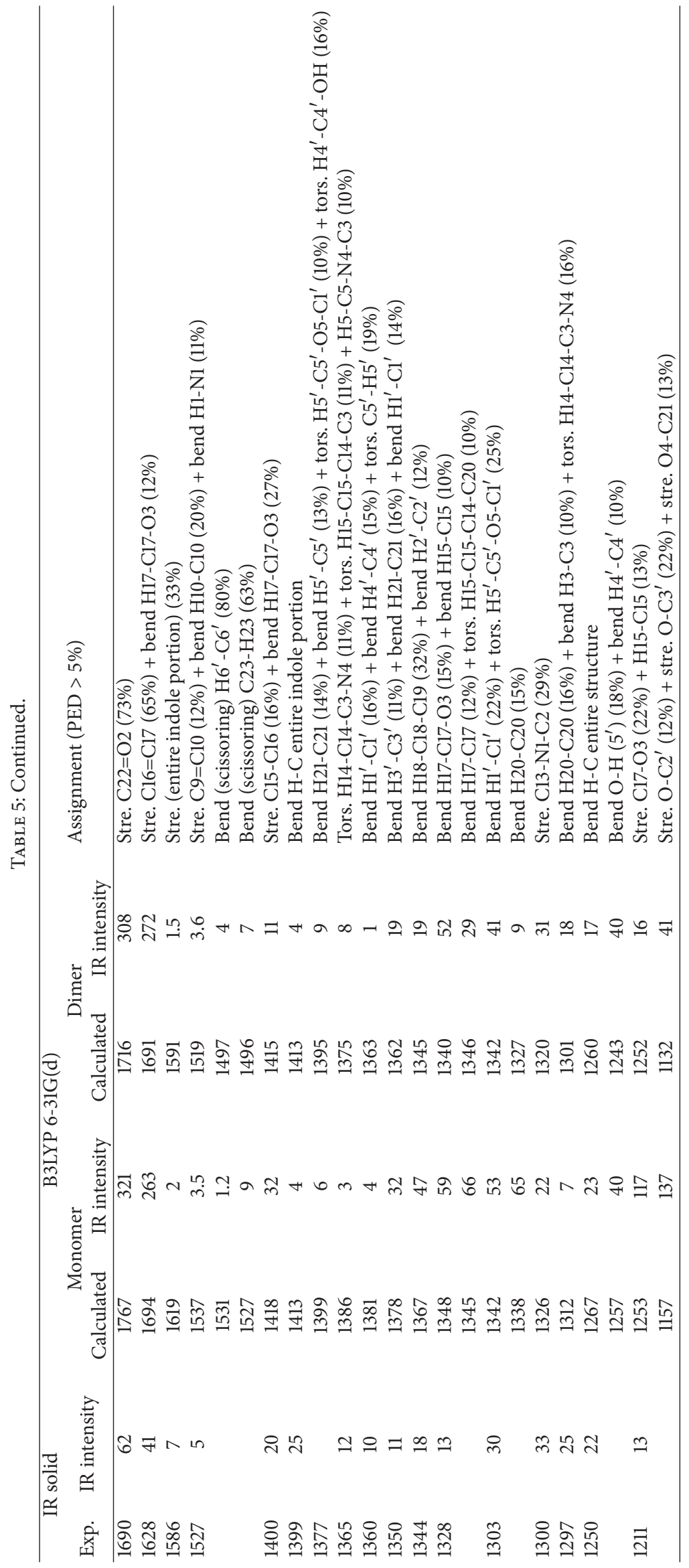




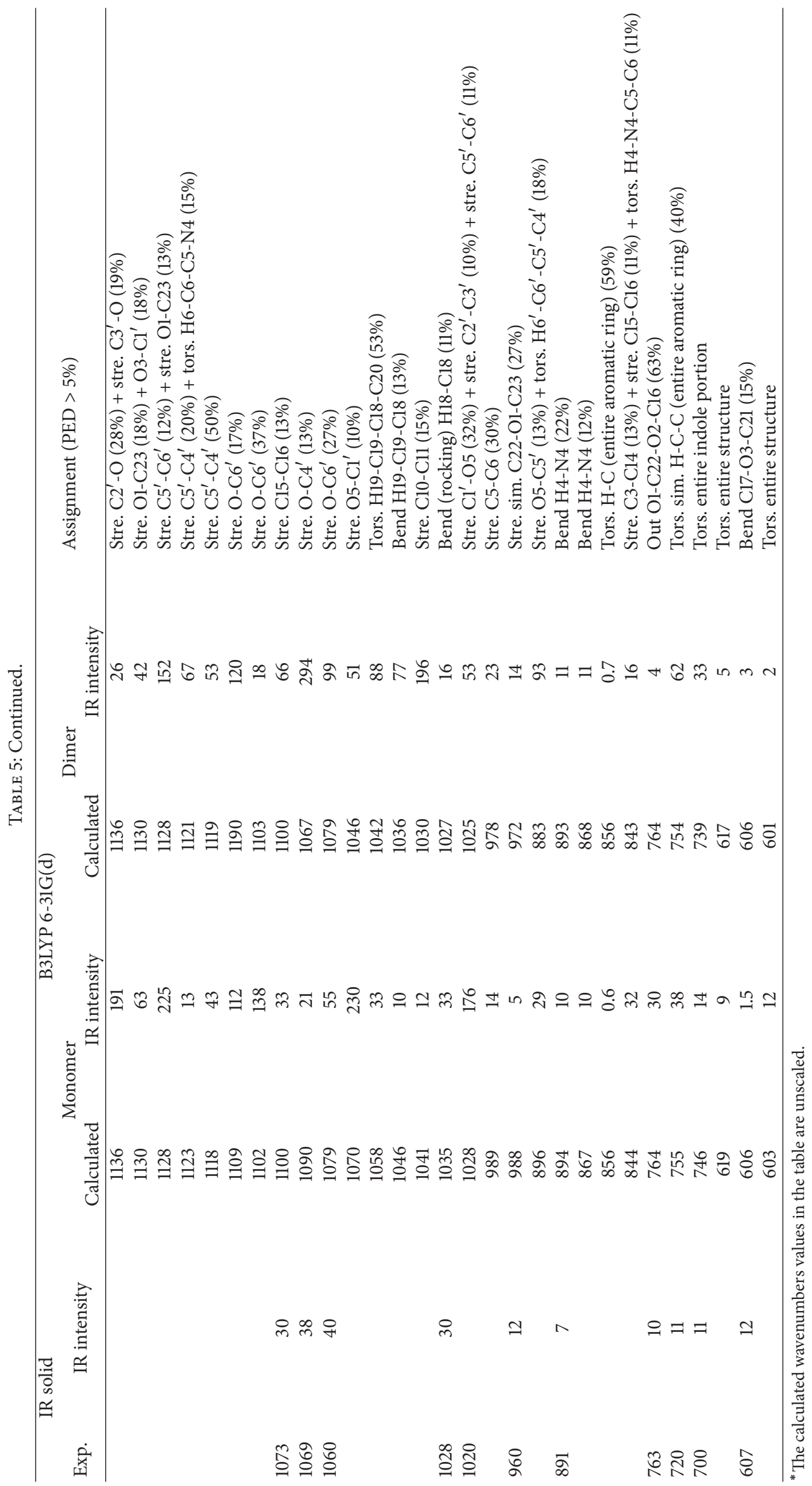




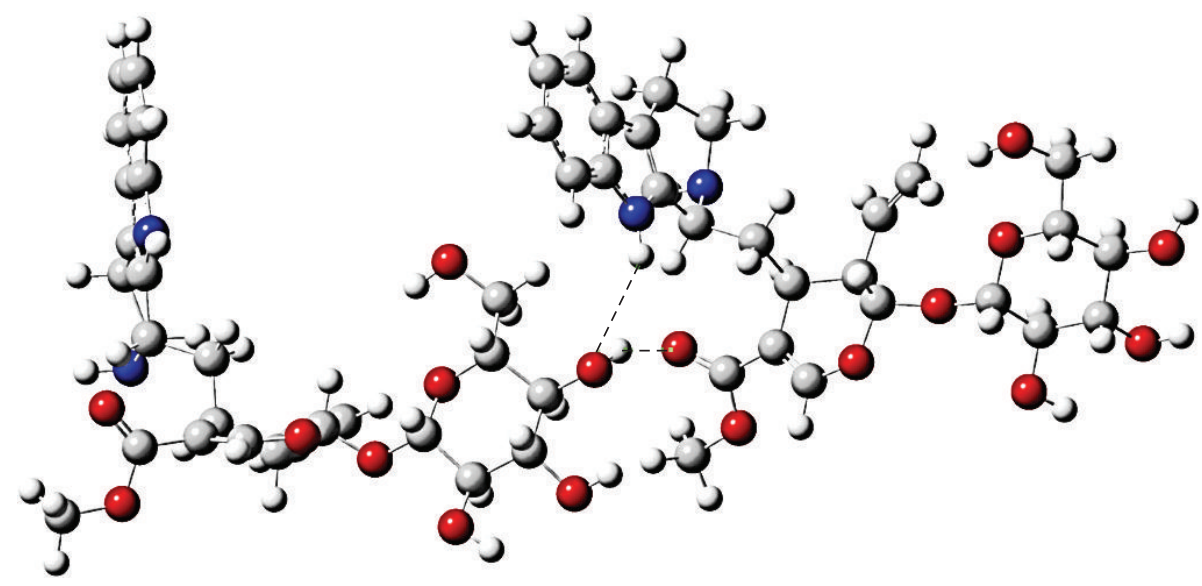

FIGURE 8: The strictosidine dimer, featuring hydrogen bonds (dashed line) between the tryptophanic and glycosidic moieties.

bonds and revealed several characteristic vibrations that may be used as a diagnostic tool for other indole alkaloids, simplifying their identification and structural characterization. The NBO calculations showed that the strongest stabilization energies for strictosidine involved hyperconjugative interactions in the indolic portion (aromatic and pentacyclic rings) and in the dihydropyran portion, justifying the few fragmentation modes for its protonated molecule observed in the $\mathrm{MS}^{n}$ analysis, and these modes may contribute to the further characterization of strictosidine analogues and derivatives.

\section{Conflict of Interests}

The authors declare that there is no conflict of interests regarding the publication of this paper.

\section{Acknowledgments}

The authors thank Dr. Doriane Picanço of the Federal University of Amazonas for the support with the botanical identification, Professor Dr. Michel Rossman for the X-ray data for loganin, Dr. Elaine H. T. Oliveira for the spelling support, and Capes and FINEP for the financial support.

\section{References}

[1] M. Frederick, M.-P. Hayette, M. Tits, P. De Mol, and L. Angenot, "In vitro activities of Strychnos alkaloids and extracts against Plasmodium falciparum," Antimicrobial Agents and Chemotherapy, vol. 43, no. 9, pp. 2328-2331, 1999.

[2] P. Rasoanaivo, S. Ratsimamanga-Urverg, R. Milijaona et al., "In vitro and in vivo chloroquine-potentiating action of Strychnos myrtoides alkaloids against chloroquine-resistant strains of Plasmodium malaria," Planta Medica, vol. 60, no. 1, pp. 13-16, 1994.

[3] R. Bassleer, M. C. Depauw-Gillet, B. Massart et al., "Effets de trois alcaloïdes extraits du Strychnos usambarensis sur des cellules cancéreuses en culture," Planta Medica, vol. 45, pp. 123$126,1982$.
[4] C. Caron, M. J. Hoizey, L. Le Men-Olivier et al., "Antimicrobial and antifungal activities of quasi-dimeric and related alkaloids," Planta Medica, vol. 54, no. 5, pp. 409-412, 1988.

[5] J. Quetin-Leclercq, A. Favel, G. Balansard, P. Regli, and L. Angenot, "Screening for in vitro antifungal activities of some indole alkaloids," Planta Medica, vol. 61, no. 5, pp. 475-477, 1995.

[6] C. L. C. de Medeiros, G. Thomas, and R. Mukherjee, "The source of $\mathrm{Ca}^{2+}$ for the spasmolytic actions of longicaudatine, a bisindole alkaloid isolated from Strychnos trinervis (Vell.) Mart. (Loganiaceae)," Phytotherapy Research, vol. 5, no. 1, pp. 24-28, 1991.

[7] V. K. Kapoor, S. K. Sharma, K. K. Chagti, and M. Singh, "Synthesis and hypotensive activity of diaboline," Indian Journal of Chemistry B: Organic Chemistry Included Medicinal. Chemistry, vol. 27, pp. 641-644, 1988.

[8] M. Tits, J. Damas, J. Quetin-Leclercq, and L. Angenot, "From ethnobotanical uses of Strychnos henningsii to antiinflammatories, analgesics and antispasmodics," Journal of Ethnopharmacology, vol. 34, no. 2-3, pp. 261-267, 1991.

[9] C. L. Cardoso, D. H. S. Silva, M. C. M. Young, I. CastroGamboa, and V. S. Bolzani, "Indole monoterpene alkaloids from Chimarrhis turbinata DC Prodr.: a contribution to the chemotaxonomic studies of the Rubiaceae family," Revista Brasileira de Farmacognosia, vol. 18, no. 1, pp. 26-29, 2008.

[10] L. F. Szabó, "Rigorous biogenetic network for a group of indole alkaloids derived from strictosidine," Molecules, vol. 13, no. 8, pp. 1875-1896, 2008.

[11] X. Huang, Y. Li, Y. Su, X. Chai, and S. Yan, "Monoterpene indole alkaloids and monoterpene diglycosides from the roots of Triosteum pinnatifidum," Phytochemistry Letters, vol. 7, no. 1, pp. 30-34, 2014.

[12] Y.-J. Xu, K. Foubert, L. Dhooghe et al., "Chromatographic profiling and identification of two new iridoid-indole alkaloids by UPLC-MS and HPLC-SPE-NMR analysis of an antimalarial extract from Nauclea pobeguinii," Phytochemistry Letters, vol. 5, no. 2, pp. 316-319, 2012.

[13] M. Tits, V. Brandt, J.-N. Wauters, C. Delaude, G. Llabres, and L. Angenot, "Glucoindole alkaloids from stem bark of Strychnos mellodora," Planta Medica, vol. 62, no. 1, pp. 73-74, 1996.

[14] G. N. Smith, "Strictosidine: a key intermediate in the biogenesis of indole alkaloids," Chemical Communications, no. 15, pp. 912914, 1968. 
[15] R. Verpoorte, R. van der Heijden, and P. R. H. Moreno, The Alkaloids, vol. 49, Academic Press, San Diego, Calif, USA, 1997.

[16] T. M. Kutchan, "Strictosidine: from alkaloid to enzyme to gene," Phytochemistry, vol. 32, no. 3, pp. 493-506, 1993.

[17] A. R. Battersby, A. R. Burnett, E. S. Hall, and P. G. Parsons, "The rearrangement process in indole alkaloid biosynthesis," Chemical Communications, vol. 24, pp. 1582-1583, 1968.

[18] A. R. Battersby, A. R. Burnett, and P. G. Persons, "Alkaloid biosynthesis. Part XV. Partial synthesis and isolation of vincoside and isovincoside: biosynthesis of the three major classes of indole alkaloids from vincoside," Journal of the Chemical Society C: Organic, vol. 20, no. 8, pp. 1193-1200, 1969.

[19] Á. Patthy-Lukáts, L. Károlyházy, L. F. Szabó, and B. Podányi, "First direct and detailed stereochemical analysis of strictosidine," Journal of Natural Products, vol. 60, no. 2, pp. 69-75, 1997.

[20] Y. Yamazaki, A. Urano, H. Sudo et al., "Metabolite profiling of alkaloids and strictosidine synthase activity in camptothecin producing plants," Phytochemistry, vol. 62, no. 3, pp. 461-470, 2003.

[21] M. J. Frisch, G. W. Trucks, H. B. Schlegel, and G. E. Scuseriaet, Gaussian 03 Revision, B.05, Gaussian, Pittsburgh, Pa, USA, 2003.

[22] C. Timmons and P. Wipf, "Density functional theory calculation of ${ }^{13} \mathrm{C}$ NMR shifts of diazaphenanthrene alkaloids: reinvestigation of the structure of samoquasine A," Journal of Organic Chemistry, vol. 73, no. 22, pp. 9168-9170, 2008.

[23] J. A. Dobado, N. Benkadour, S. Melchor, and D. Portal, "Structure and theoretical NMR chemical shifts of modified cyclodextrins," Journal of Molecular Structure: THEOCHEM, vol. 672, no. 1-3, pp. 127-132, 2004.

[24] R. Dennington, T. Keith, and J. Millam, Gaussview Version 5, Semichem, Shawnee Missions, Kan, USA, 2009.

[25] M. H. Jamroz, Vibrational Energy Distribution Analysis, VEDA 4 Computer Program, Warsaw, Poland, 2004.

[26] L. Dupont and O. Dideberg, "Structure cristalline et moleulaire d'un nouvel alcaloide indolique, l'akagerine," Acta Crystallographica B, vol. 31, pp. 2378-2383, 1975.

[27] P. Molina, P. M. Fresneda, M. A. Sanz, C. Foces-Foces, and M. C. R. de Arellano, "Investigative studies on the formation of the imidazo $\left[4^{\prime}, 5^{\prime}: 3,4\right]$ pyrido [2,3-b]indole ring: formal synthesis of the alkaloids grossularines-1 and 2. X-Ray crystal structures of 5-indol-3-yl-imidazole and bisimidazocarbazole derivatives," Tetrahedron, vol. 54, pp. 9623-9638, 1998.

[28] S. C. Nyburg, P. Y. Siew, G. N. Saunders, J. R. Purdy, and S. McLean, "X-ray crystal structure analysis of a bisepoxide derived from secologanin: the structure and absolute configuration," Canadian Journal of Chemistry, vol. 61, no. 2, pp. 282-283, 1983.

[29] P. J. Lentz and M. G. Rossmann, "The crystal structure of loganin penta-acetate monomethyl ether bromide," Journal of the Chemical Society D: Chemical Communications, no. 21, p. $1269,1969$.

[30] C. R. Hutchinson, A. H. Heckendorf, J. L. Straugh, P. E. Daddona, and D. E. Cane, "Biosynthesis of camptothecin. 3. Definition of strictosamide as the penultimate biosynthetic precursor assisted by carbon-13 and deuterium NMR spectroscopy," Journal of the American Chemical Society, vol. 101, pp. 3358-3369, 1979.

[31] A. W. Sangster and K. L. Stuart, "Ultraviolet spectra of alkaloids," Chemical Reviews, vol. 65, no. 1, pp. 69-130, 1965.
[32] N. Özdemir, S. Dayan, O. Dayan, M. Dinçer, and N. Kalaycıoglu, "Experimental and molecular modeling investigation of $(E)$ $N$-\{2-[(2-hydroxybenzylidene)amino]phenyl\} benzenesulfonamide," Journal Molecular Physics, vol. 111, no. 6, pp. 707-723, 2013.

[33] E. I. Paulraj and S. Muthu, "Molecular structure analysis and spectroscopic characterization of 5-ethyl-5-phenyl-1,3diazinane-4,6-dione with experimental (FT-IR and FT-Raman) techniques and quantum chemical calculations," Spectrochimica Acta-Part A: Molecular and Biomolecular Spectroscopy, vol. 106, pp. 310-320, 2013.

[34] R. G. Parr and W. Yang, Functional Theory of Atoms and Molecules, Oxford University Press, New York, NY, USA, 1989.

[35] R. G. Parr, L. V. Szentpály, and S. Liu, "Electrophilicity index," Journal of the American Chemical Society, vol. 121, no. 9, pp. 1922-1924, 1999.

[36] L. R. Domingo and P. Pérez, "The nucleophilicity N index in organic chemistry," Organic and Biomolecular Chemistry, vol. 9, no. 20, pp. 7168-7175, 2011.

[37] L. R. Domingo, P. Perez, and E. Chamorro.

[38] C. Stévigny, J.-L. H. Jiwan, R. Rozenberg, E. De Hoffmann, and J. Quetin-Leclercq, "Key fragmentation patterns of aporphine alkaloids by electrospray ionization with multistage mass spectrometry," Rapid Communications in Mass Spectrometry, vol. 18, no. 5, pp. 523-528, 2004.

[39] E. R. Davidson, Reduced Density Matrices in Quantum Chemistry, Academic Press, New York, NY, USA, 1976.

[40] J. E. Carpenter and F. Weinhold, "Analysis of the geometry of the hydroxymethyl radical by the 'different hybrids for different spins' natural bond orbital procedure," Journal of Molecular Structure: THEOCHEM, vol. 169, pp. 41-62, 1988.

[41] B. C Carlson, J. M. Keller, and B. C Carlson, "Orthogonalization Procedures and the Localization of Wannier Functions," Physical Reviews, vol. 105, p. 102, 1957.

[42] A. E. Reed, R. B. Weinstock, and F. Weinhold, "Natural population analysis," The Journal of Chemical Physics, vol. 83, no. 2, pp. 735-746, 1985.

[43] R. S. Mulliken, "Electronic population analysis on LCAO-MO molecular wave functions," Journal of Chemical Physics, vol. 23, pp. 1833-1841, 1955.

[44] R. S. Mulliken and W. C. Ermler, Diatomic Molecules: Results of Ab Initio Calculations, Academic Press, New York, NY, USA, 1977.

[45] J. K. Badenhoop and F. Weinhold, "Natural bond orbital analysis of steric interactions," Journal of Chemical Physics, vol. 107, no. 14, pp. 5406-5421, 1997.

[46] J. P. Foster and F. Weinhold, "Natural hybrid orbitals," Journal of the American Chemical Society, vol. 102, no. 24, pp. 7211-7218, 1980.

[47] A. E. Reed and F. Weinhold, "Natural bond orbital analysis of near-Hartree-Fock water dimer," The Journal of Chemical Physics, vol. 78, no. 6, pp. 4066-4073, 1983.

[48] V. Deval, A. Kumar, V. Gupta et al., "Molecular structure (monomeric and dimeric) and hydrogen bonds in 5-benzyl 2thiohydantoin studied by FT-IR and FT-Raman spectroscopy and DFT calculations," Spectrochimica Acta-Part A: Molecular and Biomolecular Spectroscopy, vol. 132, pp. 15-26, 2014.

[49] J. S. Murray and K. Sen, Molecular Electrostatic Potentials Concepts and Applications, Elsevier Science, Amsterdam, The Netherlands, 1996. 

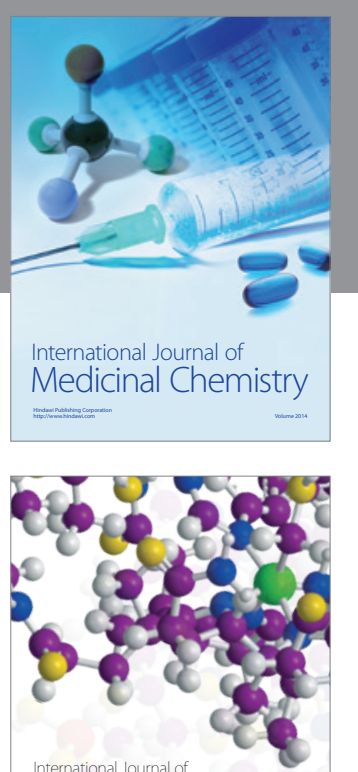

Carbohydrate Chemistry

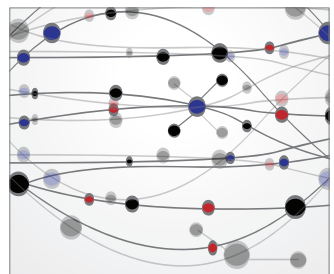

The Scientific World Journal
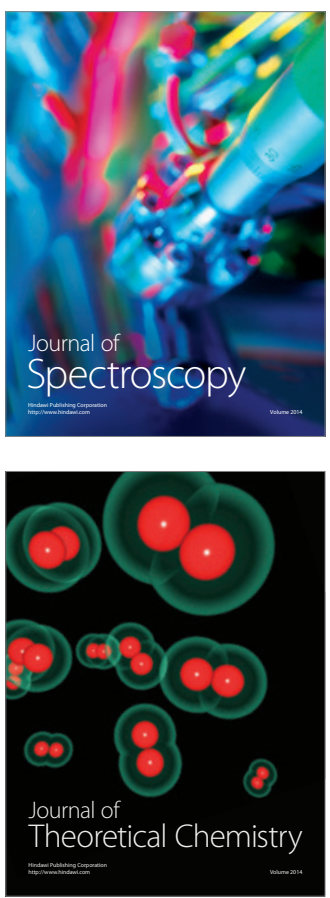
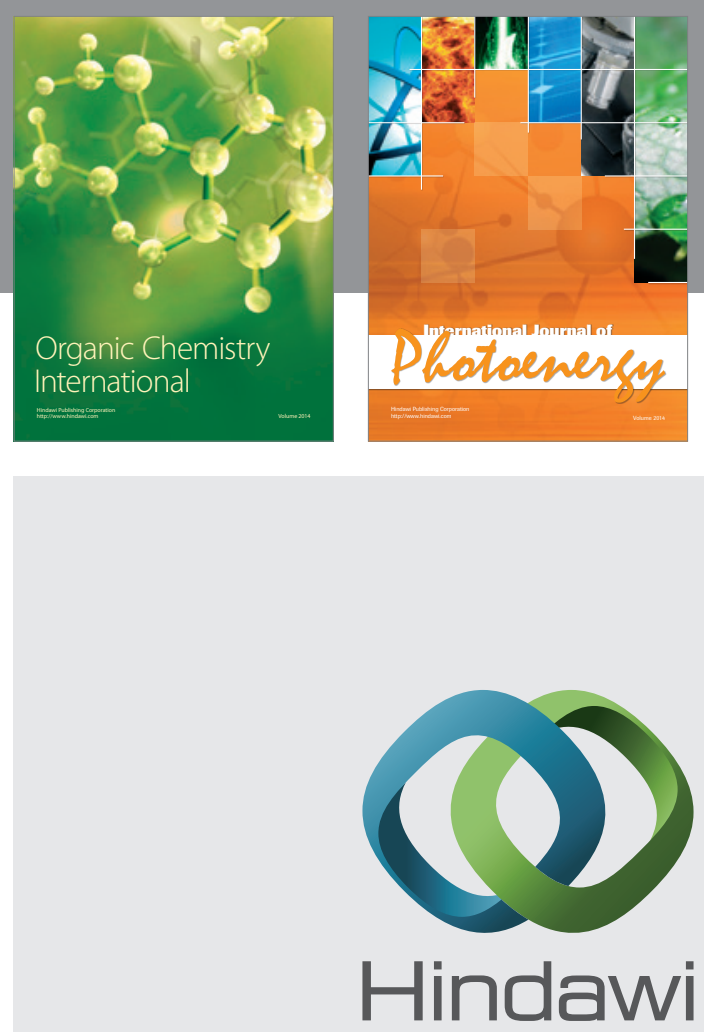

Submit your manuscripts at

http://www.hindawi.com

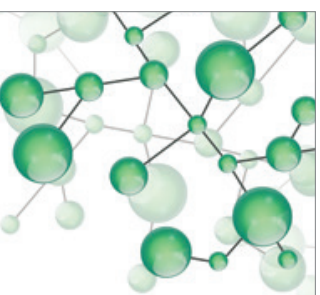

International Journal of

Inorganic Chemistry

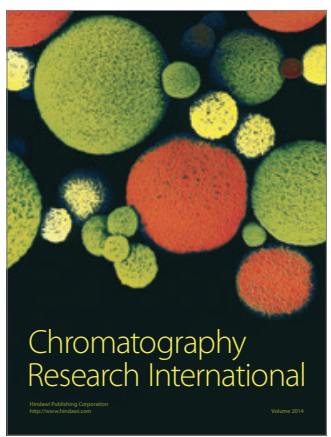

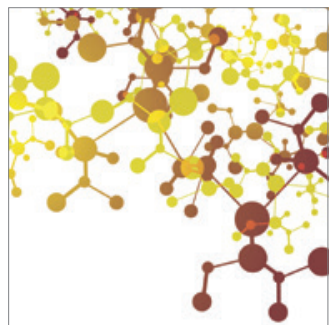

Applied Chemistry
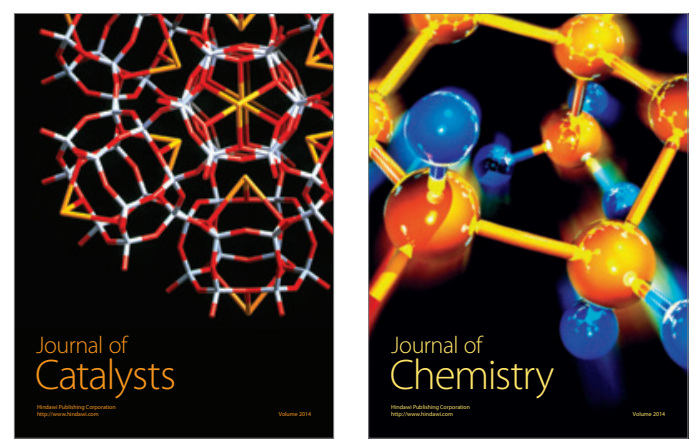
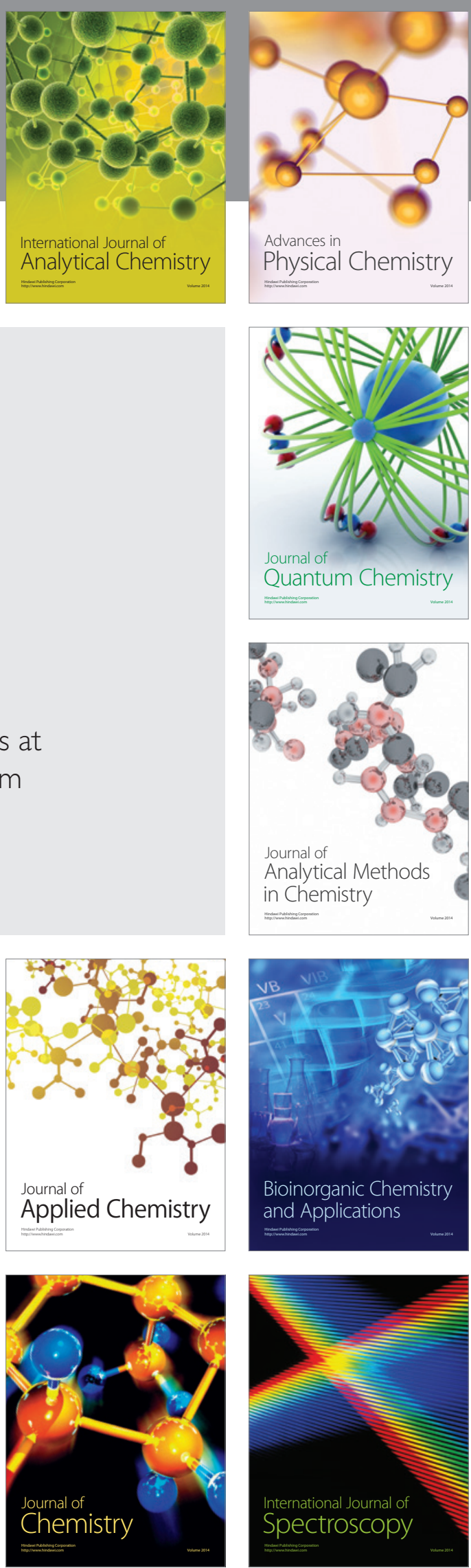